NBER WORKING PAPER SERIES

\title{
THE RETURNS ON HUMAN CAPITAL: GOOD NEWS ON WALL STREET IS BAD NEWS ON MAIN STREET
}

\author{
Hanno Lustig \\ Stijn Van Nieuwerburgh \\ Working Paper 11564 \\ http://www.nber.org/papers/w11564
}
NATIONAL BUREAU OF ECONOMIC RESEARCH
1050 Massachusetts Avenue
Cambridge, MA 02138
August 2005

The authors would like to thank Andy Atkeson, Hal Cole, Robert Hall, Hugo Hopenhayn, Chad Jones, Martin Lettau , Francis Longstaff, Sydney Ludvigson, Alex Michaelides, Tobias Moskowitz, Laura Veldkamp, and the participants of the UCLA brown bag lunch, the NYU macro-finance reading group and macrolunch, seminar participants at the University of California at Berkeley, Stanford, USC, Pompeu Fabra, the LSE, and the Bank of England, and participants of the NBER Summer Institute Asset Pricing Meetings. We have benefitted from conversations with John Heaton and Tano Santos about related ideas. We are especially grateful to John Campbell and Lars Peter Hansen for detailed comments. The views expressed herein are those of the author(s) and do not necessarily reflect the views of the National Bureau of Economic Research.

@ 2005 by Hanno Lustig and Stijn Van Nieuwerburgh. All rights reserved. Short sections of text, not to exceed two paragraphs, may be quoted without explicit permission provided that full credit, including $($ ) notice, is given to the source. 
The Returns on Human Capital: Good News on Wall Street is Bad News on Main Street Hanno Lustig and Stijn Van Nieuwerburgh

NBER Working Paper No. 11564

August 2005

JEL No. G1

\section{$\underline{\text { ABSTRACT }}$}

We use a standard single-agent model to conduct a simple consumption growth accounting exercise. Consumption growth is driven by news about current and expected future returns on the market portfolio. The market portfolio includes financial and human wealth. We impute the residual of consumption growth innovations that cannot be attributed to either news about financial asset returns or future labor income growth to news about expected future returns on human wealth, and we back out the implied human wealth and market return process. This accounting procedure only depends on the agent's willingness to substitute consumption over time, not her consumption risk preferences. We find that innovations in current and future human wealth returns are negatively correlated with innovations in current and future financial asset returns, regardless of the elasticity of intertemporal substitution. The evidence from the cross-section of stock returns suggests that the market return we back out of aggregate consumption innovations is a better measure of market risk than the return on the stock market.

Hanno Lustig

Department of Economics

UCLA

Box 951477

Los Angeles, CA 90095-1477

and NBER

hlustig@econ.ucla.edu
Stijn Van Nieuwerburgh

Department of Finance

New York University

$44 \mathrm{~W} 4^{\text {th }}$ Street

Suite 9-190

New York, NY 10012

svnieuwe@stern.nyu.edu 


\section{Introduction}

Starting with the seminal work by Breeden (1979) and Lucas (1978), much of the work in dynamic asset pricing asks whether observed aggregate consumption growth can explain or deliver financial returns like the ones we observe in the data (Grossman and Shiller (1981) and Hansen and Singleton (1983)). Mehra and Prescott (1985) point out that a very high degree of risk aversion is needed to reconcile a high equity premium with a low covariance between consumption growth and returns. Kandel and Stambaugh (1990) extend this analysis to the conditional moments of returns and consumption growth, and they reach the same conclusion. We turn this question on its head: Starting from observed returns on financial assets, what restrictions does the standard single agent model impose on the joint distribution of the market returns and aggregate consumption growth?

Following Roll (1977)'s critique, the literature has recognized the importance of including human wealth returns as part of the market return (e.g. Shiller (1995), Campbell (1996), and Jagannathan and Wang (1996)), but only the cash flow component of human wealth returns is observed, not the discount rate component. This paper uses observed aggregate consumption to learn about the human wealth returns. A standard single-agent model puts tight restrictions on the joint distribution of market returns and aggregate consumption. We exploit these restrictions to account for aggregate consumption growth, and we impute that part of consumption innovations not due to news about financial asset returns to human wealth returns.

To do so, we confront a single agent with the observed market returns on US household wealth and back out her implied consumption innovations. These consumption innovations are determined by news about current returns and by news about future expected returns on the market portfolio. The effect of news about future market returns on consumption depends only on how willing this agent is to substitute over time, not on her risk preferences (Campbell (1993)). If her portfolio only includes financial wealth, the model-implied consumption innovations are radically different from those in the data. The agent's consumption innovations are at least ten times too volatile relative to US aggregate consumption innovations and the implied correlation of her consumption innovations with news about stock returns is at least four times higher than in the data. Even when the intertemporal elasticity of substitution $(E I S)$ is zero, there is just not enough mean reversion in stock returns to reconcile the moments of consumption and returns. We call this the consumption correlation and volatility puzzle. 
These two moments of aggregate consumption growth are also at the heart of Mehra and Prescott (1985)'s equity premium puzzle. However, the volatility and correlation puzzles only depend on the agent's willingness to transfer consumption between different periods in response to news about future returns, while the equity premium puzzle only depends on the agent's aversion to consumption bets. We show that, in a model with only financial wealth, there is no value of the EIS that closes the gap between the model and the data, but large values definitely make matters worse.

We interpret this failure as a market return measurement problem, and we explicitly introduce human wealth in our single agent's portfolio, following the example of Campbell (1996) and Jagannathan and Wang (1996). In a first step, we show that a model in which the expected returns on human wealth and financial wealth are perfectly correlated, like Campbell (1996)'s, cannot come close to matching the consumption moments in the data. Models in which the expected return on human wealth is constant, like Shiller (1995)'s, or, in which the expected return on human wealth is perfectly correlated with expected labor income growth, like Jagannathan and Wang (1996)'s, do better, but these still over-predict the volatility of consumption innovations and their correlation with financial returns.

In a second step, we conduct a basic consumption growth accounting exercise. We impute that part of the consumption innovations that cannot be attributed to news about current or future financial returns to the returns on human wealth. This approach constructs a process for the expected return on human wealth that exactly matches the moments of aggregate consumption innovations in the data. We find that (1) good news about current returns in financial markets is bad news about current returns in labor markets, regardless of the EIS, and (2) the implied total market return is negatively correlated with the returns on financial wealth if the EIS is smaller than one.

The negative correlation between financial and human wealth returns has a cash-flow component and a discount rate component. First, with respect to the cash flows, we find that good news about future labor income growth is bad news for the future growth rate of pay-outs to securities holders. This is a feature of the data. Second, with respect to the discount rates, positive innovations to future risk premia on financial wealth tend to coincide with negative innovations to expected future returns on human wealth. This is what comes out of our consumption growth accounting exercise. The negative discount rate correlation for these two assets is not surprising. Santos and Veronesi (2004) were the first to analyze these composition effects on risk premia in a two-sector model ${ }^{1}$.

\footnotetext{
${ }^{1}$ Consider a simple example of the composition effect. In a two-tree Lucas endowment model with
} 
In a third step, we extend the analysis to time-varying wealth shares. Time-variation in the human wealth share enables our model to match observed consumption moments with less volatile human wealth returns.

While Campbell's work aimed to substitute consumption out of the asset pricing equations, we actually obtain better measures of market risk when the market return is forced to be consistent with the moments of aggregate consumption. We revisit the Roll critique, and ask whether our consumption-consistent capital asset pricing model improves the pricing of assets in the cross-section. Using our model-implied market returns and model-implied consumption, we find that our model produces the lowest pricing errors for size and value stock portfolios among the models that include human wealth in the market portfolio. Growth stocks provide better insurance against future human capital risk and therefore trade at a risk discount relative to value stocks.

But there is even more compelling evidence against the stock market return as a measure of the market return, that does not depend on the investor's preferences at all: The budget constraint dictates that over very long horizons consumption growth and the market returns coincide. However, in US data, news about long-run consumption growth and market returns are negatively correlated if the market portfolio only includes financial wealth, and the long-run returns are much more volatile than long-run consumption growth. Once human wealth is added to the market portfolio, they line up much better; the correlation increases to .7 at annual frequencies. Nonetheless, the long-run, model-implied market return is still more volatile than long-run consumption growth, another manifestation of the equity volatility puzzle of LeRoy and Porter (1981) and Shiller (1981). To address this shortcoming, we back out cash-flow news about human wealth from consumption growth -instead of labor income growth- data by imposing this long-run restriction, and, as before, we find the discount rate on human wealth that best matches the short-run moments of consumption. This exercises confirms our main findings: To match the properties of consumption in the data, the returns on financial and human wealth must be strongly negatively correlated.

Other Explanations We attribute the component of aggregate consumption growth that is not accounted for by financial asset returns to human wealth returns. Other labels come to mind for this residual. In the paper, we consider four in detail, and we find that

i.i.d dividend growth and log preferences, when the dividend share of the first tree increases, its expected return must go up to induce investors to hold it despite its larger share. Because the overall price-dividend ratio stays constant, the expected return on the second tree has to decrease (see Cochrane, Longstaff, and Santa-Clara (2004)). 
the usual fixes either worsen the consumption volatility and correlation puzzles, or do not help. First, if the agent's preferences display external habit formation as in Campbell and Cochrane (1999), the volatility and the correlation puzzles cannot be resolved unless through heteroscedasticity in the market return. In a second step, we test for this possibility by checking if our consumption growth residual predicts the future volatility of stock returns, and it does not. Nor does it forecast the volatility of consumption innovations or their covariance with financial returns. Third, we argue that heterogeneity makes matters worse in the empirically relevant case where financial asset holders have a higher EIS. If we want to match these moments of aggregate consumption, then the consumption of stockholders and non-stockholders has to be really negatively correlated, and this presents a serious challenge to limited participation explanations of asset pricing puzzles (Heaton and Lucas (1996) and Guvenen (2003)). Fourth, we found the same consumption correlation and volatility puzzles in annual and bi-annual data, which casts doubt on consumption adjustment cost explanations.

Finally, the omission of housing wealth may lead to the erroneous interpretation of the residual as a human wealth return. When we include housing wealth into the portfolio of the investor, the residual has the same properties as in the model without housing wealth.

Related Literature While there is a huge literature on the risk-return trade-off in financial markets, the role of risk is usually ignored when economists model human capital investment decisions. Palacios-Huerta (2001) is the first to focus on this trade-off in labor markets; he uses individual labor-income based measures of human capital returns. ${ }^{2}$ We use the information in aggregate consumption innovations instead to learn about the aggregate human wealth returns.

Bansal and Yaron (2004) deliver a consumption and dividend process that can match expected returns on financial wealth by imputing a key role to long-run consumption risk. Instead, we back out a human wealth return process that implies the right aggregate consumption behavior. Vissing-Jorgensen and Attanasio (2003) also use Campbell (1996)'s framework to estimate the EIS and the coefficient of risk aversion using household-level data. They conclude that the EIS of stockholders is likely to be above one, but they do not match the model-implied consumption volatility and correlation moments with those

\footnotetext{
${ }^{2}$ Palacios-Huerta measures returns on human capital as the proportional increase in earnings per year from the last year of schooling. He does not take into account the effect of revisions on future labor income and discount rates. Two related papers are Palacios-Huerta (2003a) and Palacios-Huerta (2003b)).
} 
in the data. Our paper adds these two consumption moments to the picture ${ }^{3}$. Our work is also related to Santos and Veronesi (2004). They set up two-sector-model, a labor-income and a capital-income generating sector; assets are priced off a conditional CAPM in which the labor income share is the conditioning variable. While the labor income share works well as a conditioning variable in explaining the cross-section of returns, they find that innovations to future labor income growth do not help much in pricing. We find that future human capital risk is priced, and that growth firms provide a better hedge against this risk.

Lettau and Ludvigson (2001a) find that the single agent's budget constraint provides useful aggregate risk information. They use a linearized version of the household budget constraint to show that the co-integration vector between consumption, financial wealth, and labor income predicts stock returns. Lettau and Ludvigson (2001b) derive a scaled version of the Consumption CAPM from this budget constraint and show it prices the cross-section of size and value portfolios. We use the budget constraint and the Euler equation to derive a consumption-consistent version of the CAPM. As a robustness check, we estimate our system imposing co-integration between consumption, financial wealth, and labor income. If anything, return on financial and human wealth must be even more negatively correlated. We find that our consumption-wealth ratio still forecasts stock returns, confirming Lettau and Ludvigson (2001a). Our market return process, derived from actual US aggregate consumption innovations, actually does better in explaining the cross-section of asset returns than the standard CAPM return on the stock market. Our results may help to understand the findings of Lewellen and Nagel (2004), who argue the CAPM betas do not vary enough in order for a conditional version of the CAPM to explain the variation in returns; stock market risk is a poor measure of market risk. Interestingly, Boyd, Hu, and Jagannathan (2005) show that on average good news about unemployment implies lower stock returns, except in recessions. Similar results are obtained by Andersen, Bollerslev, Diebold, and Vega (2005) for a wide range of macro-economic announcements. We infer from aggregate consumption that bad news for stock returns is good news for the rest of the economy.

\footnotetext{
${ }^{3}$ We are less sanguine about large values of the EIS, for two reasons. First, if the EIS is larger than one, the market return has to display multivariate mean aversion in order to match the aggregate consumption volatility, and this has counterfactual asset pricing implications in the cross-section. Second, financial returns display strong mean reversion and, according to the model, an individual investor holding only financial wealth (e.g. a retiree) would have implausibly volatile consumption, if she is very willing to substitute consumption over time.
} 
Implications Beyond Asset Pricing There seems to be less of a dichotomy between quantities and prices than suggested by some (e.g. Tallarini (2000) and Mulligan (2004)): Prices and returns put very tight restrictions on quantities. Standard production functions in business cycle models, such as the Cobb-Douglas, imply a nearly perfectly correlated return on human and financial wealth (Baxter and Jermann (1997)). Our results suggest that this is counter-factual and that we may need to think of different technologies. Models with time-varying factor elasticities, such as the one of Young (2004), may allow for a better description of the data.

Our work also has clear portfolio implications. US household portfolios are biased towards US securities. If financial and human wealth returns are negatively correlated, human wealth provides a good hedge against domestic asset return movements, rationalizing a long position in home assets. Relying on co-integration analysis, Julliard (2003) reaches the same conclusion as us, contradicting earlier results by Baxter and Jermann (1997), who conclude that introducing labor income risk unambiguously worsens the international diversification puzzle, because long-run labor income and financial income are positively correlated. This makes human wealth look like stocks. Relying on the same positive correlation between long-run labor income growth and stock returns, Benzoni, Collin-Dufresne, and Goldstein (2004) manage to explain the hump-shaped life-cycle pattern of stock market participation. Our model suggests that this mechanism may have counter-factual implications for the implied consumption of these investors. In all of these papers cited above, the evidence on the correlation between cash-flow and discount rate risk of human and financial wealth returns relies mostly on co-integration analysis. Such co-integration tests are known to have low power ${ }^{4}$. We argue that the cross-equation restrictions on consumption implied by the theory are perhaps more informative about the nature of long-run human capital risk.

We start by briefly reviewing the Campbell framework in section 2 . In section 3 , we describe the data we use and how to operationalize the model. In section 4 we describe the basic consumption correlation and volatility puzzle, and in 5 we explicitly introduce human wealth returns. In section 6.1 , we estimate the system subject to a co-integration restriction on consumption, financial wealth, and labor income and find our results to be robust. We derive the long-run restriction implied by the budget constraint in section 6.2 , and show that our main findings are robust to imposing it. Next, section 7 tests the

\footnotetext{
${ }^{4}$ For example, Hansen, Heaton, and Li (2005) show flat likelihood plots for the co-integration coefficient between consumption and earnings.
} 
asset pricing implications of our measure of market risk. Finally, in section 8 , we entertain potential alternative explanations of our findings. A separate appendix with additional derivations and results is available on the authors' web sites.

\section{Environment}

We adopt the environment of Campbell (1993) and consider a single agent decision problem.

\subsection{Preferences}

The agent ranks consumption streams $\left\{C_{t}\right\}$ using the following utility index $U_{t}$, which is defined recursively:

$$
U_{t}=\left((1-\beta) C_{t}^{(1-\gamma) / \theta}+\beta\left(E_{t} U_{t+1}^{1-\gamma}\right)^{1 / \theta}\right)^{\theta /(1-\gamma)}
$$

where $\gamma$ is the coefficient of relative risk aversion and $\sigma$ is the intertemporal elasticity of substitution $(I E S)$. Finally, $\theta$ is defined as $\theta=\frac{1-\gamma}{1-(1 / \sigma)}$. In the case of separable utility, the elasticity of intertemporal substitution (henceforth $E I S$ ) equals the inverse of the coefficient of risk aversion and $\theta$ is one. Distinguishing between the coefficient of risk aversion and the inverse of the EIS will prove important later on. Our results on the correlation structure between financial asset returns and human wealth returns only depend on the EIS, not on the coefficient of risk aversion. Epstein and Zin (1989) preferences impute a concern for long run risk to the agent. This plays potentially an important role in understanding risk premia (Bansal and Yaron (2004)).

\section{$2.2 \quad$ Trading Assets}

All wealth, including human wealth, is tradable. We adopt Campbell's notation: $W_{t}$ denotes the representative agent's total wealth at the start of period $t$, and $R_{t+1}^{m}$ is the gross return on wealth invested from $t$ to $t+1$. This representative agent's budget constraint is:

$$
W_{t+1}=R_{t+1}^{m}\left(W_{t}-C_{t}\right)
$$

Our single agent takes the returns on the market $\left\{R_{t}^{m}\right\}$ as given, and decides how much to consume. Instead of imposing market clearing and forcing the agent to consume aggregate dividends and labor income, we simply let her choose the optimal aggregate consumption process, taking the market return process $\left\{R_{t}^{m}\right\}$ as given. 


\subsection{The Joint Distribution of Consumption and Asset Returns}

Campbell (1993) linearizes the budget constraint and uses the Euler equation to obtain an expression for consumption innovations as a function of innovations to current and future expected returns. First, Campbell linearizes the budget constraint around the mean log consumption/wealth ratio $c-w$. Lowercase letters denote logs. If the consumption-wealth ratio is stationary, in the sense that $\lim _{j \rightarrow \infty} \rho^{j}\left(c_{t+j}-w_{t+j}\right)=0$, this approximation implies that:

$$
c_{t+1}-E_{t} c_{t+1}=\left(E_{t+1}-E_{t}\right) \sum_{j=0}^{\infty} \rho^{j} r_{t+1+j}^{m}-\left(E_{t+1}-E_{t}\right) \sum_{j=1}^{\infty} \rho^{j} \Delta c_{t+1+j},
$$

where $r^{m}=\log \left(1+R^{m}\right)$ and $\rho$ is defined as $1-\exp (c-w) .{ }^{5}$ In the long run, only cash flows matter -not the discount rates- and the returns on the market portfolio are completely driven by aggregate consumption growth. We return to this long-run restriction in section 6.2 .

Second, Campbell assumes consumption and returns are conditionally homoscedastic and jointly log normal, and he substitutes the consumption Euler equation:

$$
E_{t} \Delta c_{t+1}=\mu_{m}+\sigma E_{t} r_{t+1}^{m}
$$

where $\mu_{m}$ is a constant that includes the variance and covariance terms for consumption and market return innovations, back into the consumption innovation equation in (2), to obtain an expression with only returns on the right hand side:

$$
c_{t+1}-E_{t} c_{t+1}=r_{t+1}^{m}-E_{t} r_{t+1}^{m}+(1-\sigma)\left(E_{t+1}-E_{t}\right) \sum_{j=1}^{\infty} \rho^{j} r_{t+1+j}^{m},
$$

Campbell shows this agent incurs relatively small welfare losses from using this linear consumption rule. We will use this linear version of the model as our actual model.

Innovations to the representative agent's consumption are determined by (1) the unexpected part of this period's market return and (2) the innovation to expected future market returns. There is a one-for-one relation between current return and consumption innovations, regardless of the EIS, but the relation between consumption innovations and innovations to expected future returns depends on the EIS. If the agent has log utility over deterministic consumption streams and $\sigma$ is one, the consumption innovations exactly equal the unanticipated return in this period. If $\sigma$ is larger than one, the agent lowers

\footnotetext{
${ }^{5}$ Campbell (1993) shows that this approximation is accurate for values of the EIS between 0 and 4 .
} 
her consumption to take advantage of higher expected future returns, while, if $\sigma$ is smaller than one, she chooses to increase her consumption because the income effect dominates the substitution effect. As $\sigma$ approaches zero, the current consumption innovations equal the long-run market return innovations, as is apparent from comparing the linearized budget constraint in (2) and the consumption equation in (4).

This consumption function in (4) puts tight restrictions on the joint distribution of aggregate consumption innovations and total wealth return innovations. Our aim is to study the properties of aggregate consumption implied by this restriction. More specifically, we are interested in two moments of the consumption innovations: (1) the variance of consumption innovations and (2) the correlation of consumption innovations with financial return innovations. Matching these moments of the data is a major hurdle for the model with only financial wealth, because in the data financial returns and consumption innovations have a low correlation and because consumption innovations are much less volatile than financial return innovations.

\section{Data and Model Implementation}

This section discusses the measurement of financial asset returns, the computation of all the innovations that feed into consumption innovations, and finally, the relevant moments of the data.

\subsection{Measuring Financial Asset Returns}

We use two measures of financial asset returns. The first measure is the return on the value-weighted CRSP stock market portfolio: $R_{t+1}^{a}=\frac{P_{t+1}+D_{t+1}}{P_{t}}$, where $D_{t}$ is the quarterly dividend in period $t$ and $P_{t}$ is the ex-dividend price. To remove the seasonal component in dividends, we define the log dividend price ratio as

$$
d p_{t}^{a}=\log \left(\frac{.25 D_{t}+.25 D_{t-1}+.25 D_{t-2}+.25 D_{t-3}}{P_{t}}\right)
$$

The full line in figure 1 shows the dividend-price ratio, $\exp \left(d p_{t}^{a}\right)$. We follow the literature on repurchases (Fama and French (2001) and Grullon and Michaely (2002)), and adjust the dividend yield for repurchases of equity, to ensure its stationarity. The repurchase data are from Boudoukh, Michaely, Richardson, and Roberts (2004). This is the dotted line in figure 1. The dividend-price ratio adjusted for repurchases is similar to the unadjusted series until 1980, and consistently higher afterwards. 
Our second measure of financial asset returns takes a broader perspective by including corporate debt and private companies: we value a claim to US non-financial, non-farm corporations and compute the total pay-outs to the owners of this claim. The value of US (non-financial, non-farm) corporations is the market value of all financial liabilities plus the market value of equity less the market value of financial assets. The payout measure includes all corporate pay-outs to securities holders, both stock holders and bond holders. See appendix A.1 for details. The dashed line in figure 1 shows the ratio of pay-outs to securities holders to the market value of firms. Over the last two decades, the dividend yield for the firm-value measure has been much higher than the dividend yield on stocks. This is consistent with the findings of Hall (2001). The firm value dividend yield departs from the CRSP-based repurchase adjusted series after the stock market crash of 2001. This broader measure of financial wealth is our benchmark, but we also report the results using stock market wealth, simply because the latter is more commonly used.

[Figure 1 about here.]

\subsection{Computing Innovations}

We follow Campbell (1996) and estimate a VAR with log real financial asset returns $\left(r_{t+1}^{a}\right)$, real per capita labor income growth $\left(\Delta y_{t+1}\right)$, and three return predictors: the log dividend yield on financial assets $\left(d p_{t+1}^{a}\right)$, the relative T-bill return $\left(r t b_{t+1}\right)$, and the yield spread $\left(y s p_{t+1}\right)$. To be consistent with our exercises in the next section, we add the labor income share $s_{t+1}$ and real per capita consumption growth on non-durables and services to the system $\Delta c_{t+1}$. All varriables are demeaned. We stack the $N=7$ state variables into a vector $z$. The VAR describes a linear law of motion for the state:

$$
z_{t+1}=A z_{t}+\varepsilon_{t+1}
$$

with innovation covariance matrix $E\left[\varepsilon \varepsilon^{\prime}\right]=\Sigma$. The dimensions of $\Sigma$ and $A$ are $N \times N$, the dimensions of $\varepsilon$ and $z$ are $N \times T$. Finally, we also define $e_{k}$ as the $k^{\text {th }}$ column of an identity matrix of the same dimension as $A$. Table 15 in appendix A.9 reports the VAR-estimates. The top panel uses firm value returns as the measure of financial asset returns, the bottom panel uses the value-weighted stock market return instead.

Once the VAR has been estimated, we can extract the news components that drive the consumption growth innovations: we define innovations in current financial asset returns $\left\{(a)_{t}\right\}$, innovations in current labor income growth $\left\{\left(f^{y}\right)_{t}\right\}$, news about current and future 
labor income growth $\left\{\left(d^{y}\right)_{t}\right\}$, and news about future financial asset returns $\left\{\left(h^{a}\right)_{t}\right\}$ and human capital returns $\left\{\left(h^{y}\right)_{t}\right\}$ :

$$
\begin{aligned}
(a)_{t+1} & =r_{t+1}^{a}-E_{t}\left[r_{t+1}^{a}\right]=e_{1}^{\prime} \varepsilon_{t+1} \\
\left(f^{y}\right)_{t+1} & =\Delta y_{t+1}-E_{t}\left[\Delta y_{t+1}\right]=e_{2}^{\prime} \varepsilon_{t+1} \\
\left(d^{y}\right)_{t+1} & =\left(E_{t+1}-E_{t}\right) \sum_{j=0}^{\infty} \rho^{j} \Delta y_{t+1+j}=e_{2}^{\prime}(I-\rho A)^{-1} \varepsilon_{t+1} \\
\left(h^{a}\right)_{t+1} & =\left(E_{t+1}-E_{t}\right) \sum_{j=1}^{\infty} \rho^{j} r_{t+1+j}^{a}=e_{1}^{\prime} \rho A(I-\rho A)^{-1} \varepsilon_{t+1} \\
\left(h^{y}\right)_{t+1} & =\left(E_{t+1}-E_{t}\right) \sum_{j=1}^{\infty} \rho^{j} r_{t+1+j}^{y} .
\end{aligned}
$$

News about current and future financial income growth is backed out from news about asset returns:

$$
\left(d^{a}\right)_{t+1}=\left(h^{a}\right)_{t+1}+(a)_{t+1}
$$

Finally, innovations to consumption are found as:

$$
(c)_{t+1}=c_{t+1}-E_{t}\left[c_{t+1}\right]=\Delta c_{t+1}-E_{t}\left[\Delta c_{t+1}\right]=e_{7}^{\prime} \varepsilon_{t+1} .
$$

The moments of these innovations will be denoted using $V_{i, j}$ and $C_{o r r} r_{i, j}$ notation for variances and correlations respectively.

\subsection{Stylized Facts}

Table 1 summarizes the moments from the data at quarterly frequencies for the full postwar sample (1947.II-2004.III). The left panel uses the firm value returns as the measure of financial asset returns; the right panel uses stock market returns. Our benchmark case, a VAR with 1 lag, is reported in column 1. As a robustness check, we also report results obtained using a 2-lag VAR in column 2 and an annual VAR(1) in column $3 .{ }^{6}$ All variances are multiplied by 10,000. Four key stylized facts deserve mention. We focus on column 1 in the discussion.

- Firm value return innovations are about 13 times as volatile as consumption innovations. ${ }^{7}$ The standard deviation of news about financial returns is $14 \%$ for firm value

\footnotetext{
${ }^{6}$ The signs and relative magnitudes correspond to the ones reported in Campbell (1996) for monthly and annual data.

${ }^{7}$ Our measure of consumption is real per capita non-durables and services consumption. All results go
} 
returns and $16 \%$ per annum for stock returns; the same number for consumption is $1.15 \%$ per annum $\left(V_{a}\right.$ versus $\left.V_{c}\right)$. News about future financial returns is also volatile. In annualized terms, the standard deviation is $11 \%$ for firm value and $20 \%$ for stock returns $\left(V_{h^{a}}\right)$.

- Consumption innovations and return innovations are only weakly correlated: $\operatorname{Corr}_{c, a}=$ 0.17 for firm value returns and 0.185 for stock returns.

- Current return innovations are negatively correlated with news about future expected returns: there is (multivariate) mean reversion in returns on firm value $\left(\operatorname{Corr}_{a, h^{a}}=\right.$ -.48). Stock returns display even more mean reversion $\operatorname{Corr}_{a, h^{a}}$ is -.92 .

- For firm value returns, news about future dividend growth and news about future labor income growth are negatively correlated $\left(\operatorname{Corr}_{d^{y}, d^{a}}<0\right)$ as is news about current labor income growth and current dividend growth $\left(\operatorname{Corr}_{f^{y}, f^{d}}<0\right)$.

The first three facts are well-documented, at least for stock returns; the last one is not. The firm value data indicate that good cash flow news for securities holders (stock and bond holders) may not necessarily be good cash flow news for workers. For stock returns these correlations are positive, but surprisingly small. This cash flow channel plays a key role in our results. It might be even stronger in other countries: Bottazzi, Pesenti, and VanWincoop (1996) document strong negative contemporaneous correlation between wage and profit rates in a large cross-section of developed countries.

All of these stylized facts are robust to inclusion of additional forecasting variables in the VAR. They are also robust to different measures of labor income. Our benchmark measure for labor income is real, per capita compensation of all employees from the Bureau of Economic Analysis (Table 2.1 line 2). This measure excludes proprietor's income, but includes wages and salaries to government employees. Table 11 in section A.3 of the separate appendix uses two alternative measures. Most moments are virtually unchanged relative to table 1.

[Table 1 about here.]

\section{Model 1: Financial Wealth Only}

We start by abstracting from non-financial wealth, and we compare the model-implied consumption innovation behavior to aggregate US data. We call the model with only through using total personal consumption. For total consumption $V_{c}$ is .7 and $\operatorname{Corr}_{c, a}$ is 0.1 . 
financial wealth Model 1. This is a natural starting point, because (1) standard business cycle models imply that the returns on human and other assets are highly or even perfectly correlated (e.g. Baxter and Jermann (1997) $)^{8}$, and (2) in finance, it is standard practice to use the stock market return $r_{t}^{a}$ as a measure of the market return $r_{t}^{m}$ (Black (1987) and Stambaugh (1982)).

We analyze the moments of the model-implied consumption innovations in (4) with $r^{m}=r^{a}$, simply by feeding the actual innovations to financial asset returns and news about future returns into the linearized policy function of our single agent. The procedure delivers a time series for the model-implied consumption innovations. We focus on two moments in particular: the variance of consumption innovations given by:

$$
V_{c}=V_{a}+(1-\sigma)^{2} V_{h^{a}}+2(1-\sigma) V_{a, h^{a}}
$$

and their correlation with innovations to current financial asset returns:

$$
V_{c, a}=V_{a}+(1-\sigma) V_{a, h^{a}}
$$

\subsection{Fails to Match The Variance and Correlation Moments}

In the data, the standard deviation of consumption innovations is only $0.58 \%$ per quarter, compared to $6.95 \%$ per quarter for firm return innovations, and the correlation with return innovations is .17 (see Table 1). Model 1 fails miserably to match either moment for all values of EIS. Figure 2 plots the standard deviation of the model-implied consumption innovations in the top panel and their correlation with current firm value return innovations in the bottom panel. In both panels, the EIS ranges between 0 and 1.5.

In the log case $(\sigma=1)$, consumption responds one-for-one to current return innovations. The standard deviation of consumption innovations equals the standard deviation of news about current financial returns, which is $6.95 \%$ per quarter (see equation 7 ). The correlation of consumption innovations with financial asset return innovations is 1 (see equation 8).

As the EIS decreases below 1, consumption also absorbs part of the volatility of shocks to future asset returns $V_{h^{a}}$. The effect on the variance of consumption innovations can be mitigated by the mean-reversion in returns $\left(V_{h^{a}, a}<0\right)$. If $\sigma<1$, a negative covariance of current and future return innovations also lowers the covariance of consumption with

\footnotetext{
${ }^{8}$ The capital and labor dividend streams are perfectly correlated in a Cobb-Douglas production economy in which the entire, random, capital stock process is fixed exogenously (i.e. no investment choice and no depreciation). Even with investment and depreciation, standard business cycle models imply a very high correlation between human wealth and physical capital returns.
} 
current return innovations: The agent adjusts her consumption by less in response to a positive surprise if the same news lowers her expectation about future asset returns. Indeed, figure 2 illustrates that the mean reversion in returns helps to lower the implied volatility and correlation of consumption innovations somewhat, but not nearly enough. In the bottom panel we see that the correlation goes down as the EIS declines below 1, but it never reaches the observed correlation of 0.17. Even if $\sigma$ is zero - this value of the EIS maximizes the effect of the mean reversion on the volatility of consumption innovations and on their correlation with return innovations- the standard deviation of consumption innovations is off by a factor of 10 and the correlation by a factor of almost 4 .

Mean reversion in returns actually increases the volatility of consumption if the EIS exceeds one: In response to good news, the agent increases his consumption, and this effect is reinforced because the agent anticipates lower returns in the future and decides to save less as a result! The variance of consumption indeed increases in the top panel. The correlation between consumption and stock market return innovations never drops below 0.9. ${ }^{9}$

[Figure 2 about here.]

If we use stock returns instead of firm value returns, Model 1 can match the correlation moment for $\sigma=0.2$, because of the large mean-reversion in stock returns $(-0.92$, see table 1). However, the volatility of consumption innovations is off by the same order of magnitude. Also, the mean reversion of stock returns is lower in the VAR(2) model and at annual frequencies. In annual data, the implied correlation between consumption and financial asset return innovations never falls below 0.4 , even for $\sigma=0$, twice the value in the data (see figure 8 in section A.9 of the separate appendix.).

We refer to these first two facts, respectively, as the consumption volatility and the consumption correlation puzzle. These are both tied to the lack of a large financial wealth effect on aggregate consumption. Of course, these model-implied innovations are also the consumption innovations of an investor with only financial wealth, e.g. a retiree. High values of the EIS look extremely implausible, judged by the implied consumption volatility and correlations for such investor. This failure of the model reflects a market

\footnotetext{
${ }^{9}$ There is little evidence for an EIS in excess of one. Browning, Hansen, and Heckman (2000) conduct an extensive survey of the consumption literature that estimates the EIS off household data; they conclude the consensus estimate is less than one, around .5 for food consumption. The estimates from macro data are much lower. Hall (1988) concludes the EIS is close to zero. Vissing-Jorgenson (2002) finds EIS estimates of around .3-.4 for stockholders and .8-.9 for bondholders; these are larger than the IES estimates for non-asset holders. One exception is Vissing-Jorgensen and Attanasio (2003), where the EIS is estimated to be above one, based on an estimation of an equation similar to (4), they find $\sigma=1.17$ with standard error 0.47 .
} 
return measurement problem. The next section adds human wealth to the single agent's portfolio.

\section{Adding Human Wealth}

The market portfolio now includes a claim to the entire aggregate labor income stream. The total market return can be decomposed into the return on financial assets $R^{a}$ and returns on human capital $R^{y}$. For log returns, we have:

$$
r_{t+1}^{m}=\left(1-\nu_{t}\right) r_{t+1}^{a}+\nu_{t} r_{t+1}^{y}
$$

where $\nu_{t}$ is the ratio of human wealth to total wealth.

The innovation to the return on human capital equals the innovation to the expected present discounted value of labor income less the innovation to the present discounted value of future returns. The Campbell (1991) decomposition gives:

$$
r_{t+1}^{y}-E_{t}\left[r_{t+1}^{y}\right]=\left(E_{t+1}-E_{t}\right) \sum_{j=0}^{\infty} \rho^{j} \Delta y_{t+1+j}-\left(E_{t+1}-E_{t}\right) \sum_{j=1}^{\infty} \rho^{j} r_{t+1+j}^{y}
$$

A windfall in human wealth returns is driven by higher expected labor income (cash flow) growth or by lower expected risk premia (discount rates) on human wealth. In the notation of the previous section: $(y)_{t+1}=\left(d^{y}\right)_{t+1}-\left(h^{y}\right)_{t+1}$. To the econometrician, the human wealth discount rate news $\left\{\left(h^{y}\right)\right\}$ is unobserved, and therefore so are the current innovations to human wealth returns $\{(y)\}$. In section 5.1, we introduce three benchmark models (Models 2, 3, and 4) that impose assumptions on the expected return $E_{t}\left[r_{t+1}^{y}\right]$ and hence $\left\{\left(h^{y}\right)\right\}$ to render the human wealth return news $\{(y)\}$ observable. Each of these models specifies $E_{t}\left[r_{t+1}^{y}\right]$ as a particular linear function of the state. We will show that all three imply consumption moments that are at odds with the data, and these do not solve the two puzzles illustrated for Model 1 above. Our strategy is to stay within the class of linear models for the discount rate on human wealth, $E_{t}\left[r_{t+1}^{y}\right]$, and to find, within this class, the $\left\{\left(h^{y}\right)\right\}$ process that implies consumption moments consistent with the data.

Section 5.1 introduces the three benchmark models. Before presenting our results, we generalize the analysis to time-varying wealth shares (section 5.2). The results for constant wealth shares are presented as a special case in section 5.3, and we present the general results in section 5.4. 


\subsection{Models 2, 3, and 4: Benchmark Models of Expected Human Wealth Returns}

Each of the three benchmark models differ only in the $N \times 1$ vector $C$ which measures how the innovations to the expected human wealth returns relate to the state vector $z$ :

$$
E_{t}\left[r_{t+1}^{y}\right]=C^{\prime} z_{t}
$$

In Model 2, the model of Campbell (1996), expected future human wealth returns are assumed to equal expected future asset returns: $E_{t}\left[r_{t+1}^{y}\right]=E_{t}\left[r_{t+1}^{a}\right], \forall t$. Because asset returns are the first element of the VAR, we have $C^{\prime}=e_{1}^{\prime} A$. The second term in equation (10) is $-\left(h^{a}\right)_{t+1}$. In Model 3, the model of Shiller (1995), the discount rate on human capital is constant $E_{t}\left[r_{t+1}^{y}\right]=0, \forall t$, and therefore $C^{\prime}=0$. The second term in equation (10), news about future discount rates, is zero. Finally, in Model 4, the model of Jagannathan and Wang (1996), the innovation to human wealth return equals the innovation to the labor income growth rate. The underlying assumptions are that (i) the discount rate on human capital is constant, implying that the second term in equation (10) is zero, and (ii) labor income growth is unpredictable, so that the first term in equation (10) is $\Delta y_{t+1}-E_{t} \Delta y_{t+1}$. The corresponding vector is $C^{\prime}=e_{2}^{\prime} A$.

Having specified three different models for the expected returns on human wealth, or equivalently a $C$ vector, we immediately obtain a process for $\left\{\left(h^{y}\right)_{t}\right\}$, the innovations to expected future returns on human wealth:

$$
\left(h^{y}\right)_{t}=C^{\prime} \rho(I-\rho A)^{-1} \varepsilon_{t},
$$

and a process for $\left\{(y)_{t}\right\}$, the current innovation to the return on human wealth:

$$
\begin{aligned}
(y)_{t} & =\left(d^{y}\right)_{t}-\left(h^{y}\right)_{t}, \\
& =e_{2}^{\prime}(I-\rho A)^{-1} \varepsilon_{t}-C^{\prime} \rho(I-\rho A)^{-1} \varepsilon_{t} .
\end{aligned}
$$

For example, in the $J W$ model, equation (12) implies that $C^{\prime}$ needs to equal $e_{2}^{\prime} A$ for $(y)_{t+1}$ to equal $\Delta y_{t+1}-E_{t} \Delta y_{t+1}=e_{2}^{\prime} \varepsilon_{t+1}$. We can now back out the moments of the implied aggregate consumption innovations. In the next section, we do this in the context of a model with time-varying wealth shares. 


\subsection{Incorporating Time-Varying Wealth Shares}

Campbell (1996) keeps the human wealth share constant at the labor income share: $\nu_{t}=$ $\bar{\nu}=\bar{s}$. We extend his approach to deal with time-variation in the portfolio shares, a necessary extension because we allow the expected returns on both assets to differ. We first derive a linear expression for the human wealth share $\nu_{t}\left(z_{t}\right)$, and then we show how to compute consumption innovations.

\subsubsection{Computing the Human Wealth Share}

When the expected return on human wealth is a linear function of the state (with loading vector $C$ ), the $\log$ dividend-price ratio on human wealth $d p^{y}$ is also linear in the state. In particular, the demeaned log dividend-price ratio on human wealth is a linear function of the state $z$ with a $N \times 1$ loading vector $B$ :

$$
\begin{aligned}
d p_{t}^{y}-E\left[d p_{t}^{y}\right] & =E_{t} \sum_{j=1}^{\infty} \rho^{j}\left(r_{t+j}^{y}-\Delta y_{t+j}\right) \\
& =\rho\left(C^{\prime}-e_{2}^{\prime} A\right)(I-\rho A)^{-1} z_{t} \equiv B^{\prime} z_{t} .
\end{aligned}
$$

The demeaned log dividend-price ratio on financial assets is also a linear function of the state, because it is simply the third element in the VAR: $d p_{t}^{a}-E\left[d p_{t}^{a}\right]=e_{3}^{\prime} z_{t}$, and the pricedividend ratio for the market is the wealth-consumption ratio; it is a weighted average of the price-dividend ratio for human wealth and for financial wealth:

$$
\frac{W}{C} C=\frac{P^{y}}{Y} Y+\frac{P^{a}}{D} D
$$

Finally, the human wealth to total wealth ratio is given by:

$$
\nu_{t}=\frac{\frac{P^{y}}{Y} Y}{\frac{W}{C} C}=\frac{e^{-d p_{t}^{y}} s_{t}}{e^{-d p_{t}^{y}} s_{t}+e^{-d p_{t}^{a}}\left(1-s_{t}\right)}=\frac{1}{1+e^{x_{t}}},
$$

which is a logistic function of $x_{t}=d p_{t}^{y}-d p_{t}^{a}+\log \left(\frac{1-s_{t}}{s_{t}}\right)$, where $d p^{y}=-\log \left(\frac{P^{y}}{Y}\right)$. We recall that $s$ denotes the labor income share $s_{t}=Y_{t} / C_{t}$ with mean $\bar{s}$. When $d p_{t}^{a}=d p_{t}^{y}$, the human wealth share equals the labor income share $\nu_{t}=s_{t}$. In general, $\nu_{t}$ moves around not only when the labor income share changes, but also when the difference between the $\log$ dividend price ratios on human and financial wealth changes. It is increasing in the former, and decreasing in the latter.

In section A.2.2 of the appendix, we derive a linear approximation to the logistic func- 
tion in (14). The demeaned human wealth share $\tilde{\nu}_{t} \equiv \nu_{t}-\bar{\nu}=D^{\prime} z_{t}$ is a linear function of the state, with loading vector $D$ given by:

$$
D \equiv e_{6}-\bar{s}(1-\bar{s}) B+\bar{s}(1-\bar{s}) e_{3} .
$$

\subsubsection{Computing Consumption Innovations}

When wealth shares are time-varying the agent considers the effect of (future) changes in the portfolio share of each asset when she adjusts consumption to news about returns. Combining equations (4), (9), and (10), the expression for consumption innovations becomes:

$$
\begin{aligned}
&(c)_{t+1}=\left(1-\nu_{t}\right)(a)_{t+1}+\nu_{t}\left(d^{y}\right)_{t+1}-\nu_{t}\left(h^{y}\right)_{t+1} \\
&+(1-\sigma)\left(E_{t+1}-E_{t}\right) \sum_{j=1}^{\infty} \rho^{j}\left(1-\nu_{t+j}\right) r_{t+1+j}^{a} \\
&+(1-\sigma)\left(E_{t+1}-E_{t}\right) \sum_{j=1}^{\infty} \rho^{j} \nu_{t+j} r_{t+1+j}^{y} .
\end{aligned}
$$

Future returns are now weighted by future -random- portfolio shares. To deal with this complication, we define the news about weighted future financial asset returns and human wealth returns as follows:

$$
\begin{aligned}
& W_{t+1}^{1}=\left(E_{t+1}-E_{t}\right) \sum_{j=1}^{\infty} \rho^{j} \tilde{\nu}_{t+j} r_{t+1+j}^{a} \\
& W_{t+1}^{2}=\left(E_{t+1}-E_{t}\right) \sum_{j=1}^{\infty} \rho^{j} \tilde{\nu}_{t+j} r_{t+1+j}^{y} .
\end{aligned}
$$

This helps because these two objects have a recursive structure. Using these definitions, the expression for consumption innovations reduces to:

$$
\begin{array}{r}
(c)_{t+1}=\left(1-\bar{\nu}-\tilde{\nu}_{t}\right)(a)_{t+1}+\left(\tilde{\nu}_{t}+\bar{\nu}\right)\left(d^{y}\right)_{t+1}-\left(\tilde{\nu}_{t}+\sigma \bar{\nu}\right)\left(h^{y}\right)_{t+1} \\
+(1-\sigma)(1-\bar{\nu})\left(h^{a}\right)_{t+1}-(1-\sigma)\left(W_{t+1}^{1}-W_{t+1}^{2}\right) .
\end{array}
$$

When the human wealth share is constant $\left(\nu_{t}=\bar{\nu}\right.$ or $\left.\tilde{\nu}=0\right)$, we obtain the simpler expression

$$
(c)_{t+1}=(1-\bar{\nu})(a)_{t+1}+\bar{\nu}\left(d^{y}\right)_{t+1}-\sigma \bar{\nu}\left(h^{y}\right)_{t+1}+(1-\sigma)(1-\bar{\nu})\left(h^{a}\right)_{t+1} .
$$


Consumption responds one-for-one to news about current asset returns, weighted with the capital income share, and to news about discounted current and future labor income growth, weighted with the labor income share, regardless of the EIS. As in Model 1, the response to news about future asset returns is governed by $1-\sigma$. The response to news about future human wealth returns is governed by $-\sigma$. This reflects the direct effect of future human wealth risk premia on consumption and the indirect effect on the current human wealth returns (see equation 10). In the log case $(\sigma=1)$, variation in future returns or in future human wealth shares has no bearing on consumption innovations today. In any other case, our single agent responds to news about future returns weighted by the portfolio shares.

We compute the function $W_{t+1}^{1}$ and $W_{t+1}^{2}$ using value function iteration. Define the news about weighted future asset returns as $\widetilde{W}_{t+1}^{1}=E_{t+1} \sum_{j=1}^{\infty} \rho^{j} \tilde{\nu}_{t+j} r_{t+1+j}^{a}$ and $\widetilde{W}_{t+1}^{2}=$ $E_{t+1} \sum_{j=1}^{\infty} \rho^{j} \tilde{\nu}_{t+j} r_{t+1+j}^{y}$. In section A.2.3 of the appendix we exploit the recursive structure of $\widetilde{W}^{1}$ and the linearity of the human wealth share to show that $\widetilde{W}^{1}$ can be stated as a quadratic function of the state:

$$
\widetilde{W}_{t+1}^{1}\left(z_{t+1}\right)=z_{t+1}^{\prime} P z_{t+1}+d,
$$

where $P$ solves the matrix Sylvester equation

$$
P_{j+1}=R+\rho A^{\prime} P_{j} A .
$$

We solve this equation by iteration, starting from $P_{0}=0$, and $R=\rho D e_{1}^{\prime} A$. The constant $d$ in the value function equals $d=\frac{\rho}{1-\rho} \operatorname{tr}(P \Sigma)$. This also implies that the news about future returns is a quadratic function of the VAR innovations and the matrix $P$ :

$$
W^{1}\left(z_{t+1}\right)=\left(E_{t+1}-E_{t}\right) \widetilde{W}_{t+1}^{1}\left(z_{t+1}\right)=\varepsilon_{t+1}^{\prime} P \varepsilon_{t+1}-\sum_{i=1}^{N} \sum_{j=1}^{N} \Sigma_{i j} P_{i j} .
$$

which turns out to be a simple quadratic function of the VAR shocks, their covariance matrix $\Sigma$, and the matrix $P$. In the same manner we calculate $\widetilde{W}^{2}$ and $W^{2}$, replacing $R$ in equation (19) by $\rho D C^{\prime}$.

\subsection{Results With Constant Wealth Shares}

To gain intuition, we first shut down the time-variation in the human wealth share and estimate equation (18) for the three benchmark models. As in the case of Model 1, Mod- 
els 2, 3, $\&$ \& cannot match the low volatility of consumption innovations and their low correlation with financial asset return innovations. To understand this failure, we must study these models' implications for human wealth returns. One particularly useful way is to reverse the logic and to impute the part of actual consumption innovations that is not due to news about financial returns or labor income growth, to news about future human wealth returns: We fix a value of the EIS parameter $\sigma$ and we back out the innovations to future human capital returns that are implied by the observed aggregate consumption innovations. The moments of consumption are matched by construction. We can now trace back the failure of the benchmark models to the difference in the moments of human wealth returns they imply and the moments that are consistent with consumption data. The consumption data clearly tell us that good news for current financial wealth returns is bad news for current human wealth returns. The benchmark models imply a positive correlation instead.

Failure of the Benchmark Models Table 2 summarizes the moments of consumption and human capital return innovations for quarterly data, and for a calibration with constant human wealth share $\bar{\nu}=\bar{s}=.70$, and $E I S$ of $\sigma=.28$, a compromise between the macroestimates of Hall (1988) -close to zero- and the consensus estimate of .5 for micro data (see Browning, Hansen, and Heckman (2000)). The left panel reports the results using firm value returns; the right panel is for stock returns. Columns 1-3 in each panel report the properties of human wealth returns and consumption for Model 2 (Campbell (1996)), Model 3 (Shiller (1995)), and Model 4 (Jagannathan and Wang (1996)).

[Table 2 about here.]

Because it equates expected future human wealth and financial wealth returns, Model 2 sets: $V_{h^{y}}=V_{h^{a}}, \operatorname{Corr}_{a, h^{y}}=\operatorname{Corr}_{a, h^{a}}, \operatorname{Corr}_{d^{y}, h^{y}}=\operatorname{Corr}_{d^{y}, h^{a}}, \operatorname{Corr}_{h^{a}, h^{y}}=1$. To understand the implications of these assumptions, Table 3 lists the sign of the effect of each variable's variance and all covariances on the variance of model-implied consumption $V_{c}$ and its covariance with financial return innovations $V_{c, a}$. For example, a positive $(4,4)$ entry in the top panel means that a higher $V_{h^{y}}$ implies a higher $V_{c}$. Indeed, for Model 2, the news about future expected returns on human capital is very volatile; as volatile as the news about financial returns. This volatility is one contributing factor to the high variance of consumption. The negative $(1,4)$ entries in the top and bottom panels show that $\operatorname{Corr}_{a, h^{y}}$ has a negative effect on $V_{c}$ and $\operatorname{Corr}_{c, a}$. But since Model 2 sets it equal to $\operatorname{Corr}_{a, h^{a}}$, the 
mean reversion in the financial return data acts to increase the variance of consumption innovations and the correlation of financial return innovations and consumption innovations. Intuitively, when good news in the stock market also leads to lower future risk premia on human wealth, positive consumption responses are magnified. Likewise, $\operatorname{Corr}_{d^{y}, h^{y}}$ negatively affects $V_{c}$ and $\operatorname{Corr}_{c, a}$, but because $h^{a}$ and $d^{y}$ are negatively correlated in the data, the assumption $\operatorname{Corr}_{d^{y}, h^{y}}=\operatorname{Corr}_{d^{y}, h^{a}}$ again increases $V_{c}$ and $\operatorname{Corr}_{c, a}$. The only assumption that helps to reduce the variance of consumption and the correlation with financial asset returns is $\operatorname{Corr}_{h^{a}, h^{y}}=1$ (when $\sigma<1$ ). The net result is that aggregate consumption innovations in Model 2 are much too volatile (by a factor of 4.3 in panel A and 4.8 in panel B) and much too highly correlated with return innovations (by a factor of 5.6 in panel A and 5.2 in panel B).

[Table 3 about here.]

We expect Model 3 to do better by assuming a constant discount rate for human capital, because this implies that $V_{h^{y}}=\operatorname{Corr}_{a, h^{y}}=\operatorname{Corr}_{d^{y}, h^{y}}=\operatorname{Corr}_{a, h^{y}}=0$, all of which help to lower the variance and correlation moment compared to Model 2. Indeed, the variance of consumption is 4.30 per quarter and the correlation moment is .865, lower than the 6.05 and .946 of Model 2. However, they are still far away from the observed magnitudes. When we use stock returns instead of the returns on firm value (panel B), the predicted correlation of innovations in consumption decreases to 0.518 , because stock market returns display more mean reversion. The variance of consumption news is still off by an order of magnitude, and the correlation by a factor of 2.8 .

Model 4 further improves the results. News in future human wealth returns equals news in future labor income growth. This means $V_{h^{y}} \approx V_{d^{y}}{ }^{10}$ In the data, news in future labor income growth is not very volatile, especially compared to news in future financial asset returns. Also $\operatorname{Corr}_{h^{y}, a} \approx \operatorname{Corr}_{d^{y}, a}>0$, a good assumption, because we know from table 3 that $\operatorname{Corr}_{h^{y}, a}>0$ helps to lower the volatility and correlation of consumption innovations when the IES is smaller than one. Yet, quantitatively, these correlations are too small in absolute magnitude to improve on Model 3.

The variance of innovations to current human wealth returns $\left(V_{y}\right)$ and their correlation with financial asset returns $\left(\mathrm{Corr}_{y, a}\right)$ are good summary statistics of our findings. Model 2 does worse than the other two because the high volatility of human capital returns and their high correlation with innovations in financial asset returns impute too much volatility

\footnotetext{
${ }^{10}$ More precisely: $V_{h^{y}}=V\left[\left(E_{t+1}-E_{t}\right) \sum_{j=1}^{\infty} \rho^{j} \Delta y_{t+1+j}\right]$. Note that $\left(E_{t+1}-E_{t}\right) \sum_{j=1}^{\infty} \rho^{j} \Delta y_{t+1+j} \neq d^{y}$ because of the summation index that starts at 1 instead of 0 .
} 
to consumption and too much correlation with financial wealth returns. The difference in the correlation moment is especially stark using stock returns (panel B): $\operatorname{Corr}_{y, a}=.93$ for Model 2, 0.49 for Model 3, and 0.07 for Model 4.

Lower Frequencies The same exercise using annual data produces similar results; the discrepancy between the model and the data increases at annual frequencies because the mean reversion in stock returns decreases. The lowest standard deviation for consumption news is $3.74 \%$ for Model 4, compared to $.80 \%$ in the data. The results are in Table 16 in section A.9 of the separate appendix. We also studied bi-annual data and we obtained similar results ${ }^{11}$. The results for model-implied human wealth shares and consumption display exactly the same features as in Table 16. We conclude that sampling consumption at lower frequencies does not alleviate the puzzles nor changes the solution.

Parameter Robustness These results are robust to plausible changes in parameter values. Figure 3 plots the model-implied standard deviation of consumption innovations and the correlation of consumption innovations with innovations in financial market returns for different values of $\sigma$ (the labor share $\bar{\nu}$ is .70). None of the models comes close to matching the variance and correlation, even for very low $\sigma$. Figure 4 shows that a labor income share of close to 1 is needed to match both consumption moments. For example, an increase in the average labor income share from 0.70 to .85 brings the standard deviation of consumption in Model 4 down to 2.3 times its value in the data; the correlation is still much too high (0.78).

[Figure 3 about here.]

[Figure 4 about here.]

Consumption-Consistent Human Wealth Returns Sofar we have been unable to bring the model's moments closer to matching those in the data. We now treat the expected returns component of human wealth return innovations as a residual and we reverseengineer a human wealth return process that can match the consumption data. The innovations in this period's consumption growth can be recovered from the VAR residuals (see equation (6)). Plugging these consumption innovations back in the household's linear

\footnotetext{
${ }^{11}$ While the correlation between bi-annual consumption growth and bi-annual stock returns increases to 0.26 , the correlation with bi-annual firm value returns is 0.00 . Details are available from the authors upon request.
} 
policy rule (18), we can back out the implied news in future human capital returns:

$$
\left(h^{y}\right)_{t+1} \equiv \frac{1}{\sigma \bar{\nu}}\left[(1-\bar{\nu})(a)_{t+1}+\bar{\nu}\left(d^{y}\right)_{t+1}+(1-\sigma)(1-\bar{\nu})\left(h^{a}\right)_{t+1}-(c)_{t+1}\right]
$$

From this $\left(h^{y}\right)$ and the data on labor income growth, we form innovations in current human wealth returns $(y)_{t+1}=\left(d^{y}\right)_{t+1}-\left(h^{y}\right)_{t+1}$.

The fourth column of each panel of Table 2 reports the properties of human wealth returns implied by consumption data and the baseline parameter calibration $\bar{\nu}=.70$ and $\sigma=.28$ (label Reverse). What are the properties of human wealth returns that enable us to match the two consumption moments? The main feature is the negative correlation between innovations to human and financial wealth returns: $\mathbf{C o r r}_{\mathbf{y , a}}<\mathbf{0}$. It is helpful to break up the human wealth return $(y)$ into news about cash flows on human wealth $\left(d^{y}\right)$ and news about discount rates $\left(h^{y}\right)$.

$$
\begin{aligned}
\operatorname{Cov}[y, a] & =\underbrace{\operatorname{Cov}\left[d^{y}, a\right]}_{\oplus}-\underbrace{\operatorname{Cov}\left[h^{y}, a\right]}_{\oplus}<0 \\
& =\underbrace{\operatorname{Cov}\left[d^{y}, d^{a}\right]}_{\text {cash flows }}-\underbrace{\operatorname{Cov}\left[d^{y}, h^{a}\right]}_{\ominus}-\underbrace{\operatorname{Cov}\left[h^{y}, d^{a}\right]}_{\oplus}+\underbrace{\operatorname{Cov}\left[h^{y}, h^{a}\right]}_{\ominus}
\end{aligned}
$$

In the data, periods with good news about current financial asset returns tend to also be periods with good news about current and future labor income growth $\left(\operatorname{Corr}_{d^{y}, a}>0\right.$, see Table 1). To prevent our single agent from going on a consumption binge, good news for current financial asset returns needs to coincide with higher future risk premia on human wealth. That is exactly what our algorithm accomplishes $\left(\operatorname{Corr}_{h^{y}, a}=.84>0\right)$. If we dig a bit deeper, we can further decompose each term into two underlying components.

Decomposing the first (cash flows) term, we uncover two opposing effects: good news about future cash flows for human wealth coincides with bad news about future cash flows for financial assets -this is the cash flow channel we mentioned earlier- but also with lower future risk premia on financial assets $\left(\operatorname{Corr}_{d^{y}, d^{a}}<0\right.$ and $\left.\operatorname{Corr}_{d^{y}, h^{a}}<0\right)$. Both are features of the data. The former helps to keep the volatility of consumption in check, but the latter hurts.

This brings us to the decomposition of the second (discount rate) term. The algorithm fights this last effect by choosing future discount rates on human wealth $\left(h^{y}\right)$ that are high when expected future dividend growth is high $\left(\operatorname{Corr}_{h^{y}, d^{a}}>0\right)$ and future risk premia on financial assets are low $\left(\operatorname{Corr}_{h^{y}, h^{a}}<0\right)$. This is the discount rate channel. So, good news 
on Wall Street is Bad news on Main street, both for cash-flows (first term) and for discount rates (second term).

Of our three benchmark models, only Model 4 delivers the same correlation pattern for $h^{y}$ as in column Reverse: $\operatorname{Corr}_{a, h^{y}}$ and $\operatorname{Corr}_{h^{y}, d^{y}}$ are positive and $\operatorname{Corr}_{h^{a}, h^{y}}$ is negative, but none of them imply $\operatorname{Corr}_{a, y}<0$.

Volatility of Human Wealth returns For the benchmark parameters and firm value returns, innovations to current and future human wealth returns $V_{y}$ and $V_{h^{y}}$ are highly volatile, 1.4 and 1.8 times as volatile as the innovations to current and future financial asset returns respectively. On the other hand, if we use stock returns instead, human wealth returns are less volatile because stock returns are more strongly mean reverting. The volatility proportionality factors are .85 and .75 . As we show in the next section, the volatility of human wealth returns also declines with the EIS and the labor income share.

The Return on the Market Portfolio In the model with constant wealth shares, innovations in the current market return are $(m)_{t+1}=(1-\bar{\nu})(a)_{t+1}+\bar{\nu}(y)_{t+1}$ and news in future market returns are given by $\left(h^{m}\right)_{t+1}=(1-\bar{\nu})\left(h^{a}\right)_{t+1}+\bar{\nu}\left(h^{y}\right)_{t+1}$ (see equation 9). The bottom four rows of table 2 display the moments of the market return.

In the three benchmark models, innovations in the market return are positively correlated with innovations in financial asset returns and human wealth returns. In contrast, in column Reverse, good news in financial markets is bad news for the current market return $\operatorname{Corr}_{m, a}<0$, simply because $\operatorname{Corr}_{y, a}<0$ and human wealth represents $70 \%$ of the market portfolio. In panel B, where we use stock returns instead, $\operatorname{Corr}_{m, a}$ is slightly positive, but we show in extensions below that this is not a robust finding. In both cases, the market return is strongly mean reverting $\operatorname{Corr}_{m, h^{m}}<-.99$. When $\sigma<1$, returns must display strong (multivariate) mean-reversion to lower consumption volatility and its correlation with the market return. Since there is not enough mean-reversion in financial returns, our reverse-engineered discount rates for human wealth create more mean-reversion in the market return, in order to match the consumption moments. We found the same results for annual data (Table 16 in section A.9 of the separate appendix). The only difference is that $\operatorname{Corr}_{m, a}$ is now also negative for stock returns. 


\subsection{Results with Time-Varying Wealth Shares}

In this section, we show that the previous results are preserved when the human wealth share vary over time (as described in section 5.2). We briefly revisit each of the three benchmark models, and show that accounting for time-varying wealth shares does not help much. Then, we estimate the vector $C$, which determines expected returns on human wealth, that most closely matches the moments of consumption. As before, the resulting human wealth returns are negatively correlated with financial asset returns.

Figure 5 plots the human wealth share over time for the three benchmark models, alongside the labor income share. Models $3 \& 4$ imply quite some variation in the human wealth share, because the risk premia on human wealth and financial wealth are not or weakly correlated; e.g. in the 90 's, the human wealth share is very low, while it is much higher in the 80's. In Model 2, the human wealth share follows the exact opposite pattern.

[Figure 5 about here.]

Columns 1-3 of Table 4 report the model-implied moments of consumption, human wealth returns and the market return for the three benchmark models. The table has the same structure as Table 2, but now with time-varying wealth shares. As is clear from equations (11) and (12), the processes for news in future and current human wealth returns only depend on the vector $C$, and not the human wealth share (vector $D$ ). Since $C$ is fixed for the benchmark models, the first seven rows of Table 4 are identical to the first seven rows of Table $2,{ }^{12}$ but the model-implied consumption innovations, specified in equation (17), do depend on the wealth shares. Rows 8 and 9 show that allowing for time-varying human wealth shares does not help to bring the benchmark models' consumption moments closer to the data. In panel A (firm value returns), $V_{c}$ and $C o r r_{c, a}$ are slightly lower, but, in panel $\mathrm{B}, V_{c}$ is slightly higher. As before, the reason is that all three models imply a high correlation between financial asset returns and the market return (row 11). Because financial asset returns are so volatile, consumption ends up being too volatile and too highly correlated with financial asset returns.

[Table 4 about here.]

\footnotetext{
${ }^{12}$ In Model 2, the conditional moments of future asset returns and human wealth returns are identical. As a result, $\left(h^{y}\right)_{t}=\left(h^{a}\right)_{t}$, which implies $W_{t}^{1}-W_{t}^{2}=0$ for all $t$. The latter can be shown by applying the law of iterated expectations. In Model $3, h^{y}=0$ and $W_{t}^{2}=0$. In Model 4 model, $W_{2}=\left(E_{t+1}-\right.$ $\left.E_{t}\right) \sum_{j=1}^{\infty} \rho^{j} \tilde{\nu}_{t+j} \Delta y_{t+1+j}$
} 
Model 5: Consumption Growth Accounting As in section 5.3, we now ask what properties human wealth returns must have to imply consumption moments consistent with the data. When human wealth shares vary over time, the procedure of backing out those properties directly from consumption data (equation 20) is no longer available. Instead, we choose the vector $C$, which relates the expected return on human wealth to the state vector, $E_{t}\left[r_{t+1}^{y}\right]=C^{\prime} z_{t}$, to minimize the distance between the model-implied consumption volatility and correlation moments and the same moments in the data. This vector then delivers human wealth return processes $\left\{h_{t}^{y}\right\}$ and $\left\{y_{t}\right\}$ from equations (11) and (12). Once we pinned down the vector $C$, we can also solve for the human wealth share from equations (13) and (15). For a given value of the EIS, equation (17) delivers the consumption innovations, which we use to compute the consumption moments. ${ }^{13}$ We label the model with the $C$ that minimizes the distance between consumption in the model and in the data Model 5; its moments are reported in the fourth column of Table 4 for $\sigma=.28$.

Whereas time-varying wealth shares did not change the results for Models 2, 3, 844 much, the results for Model 5 are somewhat different from the ones in column Reverse of Table 2. Time-variation in the human wealth share allows the model to match the moments of consumption (rows 8 and 9) for human wealth returns that are twenty percent less volatile in panels A and B. As a result, the market return processes are much less volatile as well. When the dividend yield on human wealth increases relative to the dividend yield on financial wealth, future returns on human wealth are predicted to be higher than future returns on financial wealth, but, this is counteracted by the lower human wealth share $\left(\nu_{t}\right.$ decreases in $\left.d p_{t}^{y}-d p_{t}^{a}\right)$. Time variation in the human wealth share reduces the volatility of the market return, and hence consumption. Figure 6 plots the model-implied human wealth share at the optimal parameter values, alongside the observed labor income share. The human wealth share is more than twice as volatile as the labor income share.

[Figure 6 about here.]

The main findings are strengthened: The human wealth return process is consistently negatively correlated with financial asset returns $\left(\operatorname{Corr}_{h^{y}, h^{a}}<0\right.$ and especially $\operatorname{Corr}_{y, a}<$ $0)$. These correlations are more negative than with constant wealth shares.

Varying the EIS We also investigated the sensitivity of the results to the choice of the EIS parameter $\sigma$. The results are reported in table 5. Reading across the columns, for

\footnotetext{
${ }^{13}$ We use a non-linear least squares algorithm to find the vector $C$ that minimizes the distance between the two model-implied and the two observed consumption moments. Because the moments are highly non-linear in the $N \times 1$ vector $C$, we cannot rule out that the $C$ vector is not uniquely identified.
} 
each of the calibrations, we get strong negative correlations between news about current and future financial and human wealth returns, as well as high and positive correlations $\operatorname{Corr}_{a, h^{y}}$ and $\operatorname{Corr}_{y, h^{a}}$. Good news about current financial asset returns raises risk premia on future human wealth returns and good news about current human wealth returns increases future risk premia on financial assets. These features enable Model 5 to match the smooth consumption series and its low correlation with financial asset returns (rows 8 and 9 ). The volatility of human wealth returns decreases in $\sigma ; V_{h^{y}}$ and $V_{y}$ are much lower than in Table for $\sigma=.28$.

\section{[Table 5 about here.]}

What also changes across the columns are the properties of the market return. The correlation between innovations in the market return and innovations in the human wealth returns is 0.9 in the case of $\sigma=.5$ (column 1, row 12), whereas the correlation with innovations in financial asset returns is -.7 (row 11). The implied market returns are strongly mean-reverting, as shown by the correlation between $m$ and $h^{m}$ of -.95 (row 13). In column $2, \sigma=1$ and the consumption innovation equation (16) specializes to:

$$
(c)_{t+1}=\left(1-\nu_{t}\right)(a)_{t+1}+\nu_{t}\left(d^{y}\right)_{t+1}-\nu_{t}\left(h^{y}\right)_{t+1}=\left(1-\nu_{t}\right)(a)_{t+1}+\nu_{t}(y)_{t+1}=(m)_{t} .
$$

Indeed, we find that $V_{c}=V_{a}$ and $V_{c, a}=V_{m, a}$. When the agent is myopic, her consumption responds one-for-one to innovations in the market return. In the more-than-log case $(\sigma=$ 1.5 in column 3 ), the market return must display mean aversion to match the consumption moments $\left(\operatorname{Corr}_{m, h^{m}}>0\right)$, and this is accomplished by choosing a human wealth return process that implies large enough positive correlations $\operatorname{Corr}_{a, h^{y}}$ and $\operatorname{Corr}_{y, h^{a}}$ to overcome the mean reversion in financial asset returns and human wealth returns $\left(\operatorname{Corr}_{a, h^{a}}<0\right.$ and $\left.\operatorname{Corr}_{y, h^{y}}<0\right)$. As $\sigma$ increases, the negative correlation between future expected financial and human wealth returns needs to be larger in absolute value, implying in turn a more positive correlation between $y$ and $h^{a}$. Intuitively, as the agent becomes more willing to substitute over time and $\sigma>1$, only an increase in human wealth risk premia can prevent him from consuming more when risk premia on financial returns go down.

Robustness: Different Income Measures Our results are robust to including proprietor's income in the income measure and to excluding government and non-financial employees' wages (see section A.3 in separate appendix). Importantly, when we a use a 
broader measure of labor income, the implied volatility decreases by roughly fifty percent, as a result of the increase in the average share of human wealth in the market.

\section{Long-Run Implications}

Sofar, we focused on matching the high-frequency moments of consumption and returns, but the model also has important implications for the joint distribution of consumption and market returns over longer horizons. That is the focus of this section. We start by checking whether imposing co-integration between consumption, financial wealth and labor income changes our results, and we find it does not. In a second step, we focus on the relation between consumption growth and market returns in the long run.

\subsection{Imposing Cointegration}

Lettau and Ludvigson (2001a) find evidence for a long-run relation between consumption, household net worth, and labor income, and call the deviation from this co-integration relationship cay. In this section, we investigate whether the results change when cay is added to the state vector $z$. When consumption, financial wealth and human wealth are co-integrated, this imposes restrictions on the state transition matrix $A$ and on the errors $\varepsilon$ that must be imposed. We focus on the case with a constant human wealth share $\bar{\nu}$ and find that all our results are qualitatively unchanged.

Constructing cay Our measure of financial wealth $a_{t}$ is either the CRSP stock market capitalization (corresponding to our measure of stock returns) or the total market value of non-farm non-financial business (corresponding to firm value returns). Appendix A.2.5 shows that in our model, the consumption-wealth ratio can be written as

$$
\operatorname{cay}_{t}=c_{t}-(1-\bar{\nu}) a_{t}-\bar{\nu} y_{t}
$$

Consistent with the previous analysis, we set $\bar{\nu}$ equal to the sample average of 0.7317 and use our quarterly data on $(c, a, y)$ to compute cay.

The correct specification of the state vector is now a Vector Error Correction Model (VECM):

$$
z_{t+1}=A z_{t}+\Gamma c a y_{t}+\varepsilon_{t+1}
$$

with innovation covariance matrix $E\left[\varepsilon \varepsilon^{\prime}\right]=\Sigma$. The dimensions of $\Gamma$ and cay are $N \times 1$ and 
$1 \times T$. Following Cochrane (1994), we can rewrite this VECM in VAR form:

$$
\left[\begin{array}{c}
z_{t+1} \\
\operatorname{cay}_{t+1}
\end{array}\right]=\left[\begin{array}{cc}
A & \Gamma \\
\tilde{A} & \tilde{\Gamma}
\end{array}\right]\left[\begin{array}{c}
z_{t} \\
\operatorname{cay}_{t}
\end{array}\right]+\left[\begin{array}{c}
\epsilon_{t+1} \\
\tilde{\epsilon}_{t+1}
\end{array}\right]
$$

where

$$
\begin{gathered}
\tilde{A}=A_{7 .}-(1-\bar{\nu}) A_{1 .}-\bar{\nu} A_{2 .}, \\
\tilde{\Gamma}=1+\Gamma_{7}-(1-\bar{\nu}) \Gamma_{1}-\bar{\nu} \Gamma_{2}, \\
\tilde{\varepsilon}=\left(\Sigma_{7 .}-(1-\bar{\nu}) \Sigma_{1 .}-\bar{\nu} \Sigma_{2 .}\right) \varepsilon,
\end{gathered}
$$

and $A_{7}$. denotes the $7^{\text {th }}$ row of the matrix $A$.

The co-integration relationship imposes restrictions on the last equation of the $\widehat{c a y}$ augmented VAR. We estimate $A, \Gamma$, and $\Sigma$ from the VECM in (22) and construct the augmented VAR according to equation (23). The rest of the analysis goes through as before, but with the augmented VAR. Appendix A.2.5 fills in the details.

Results Table 6 displays the moments of consumption and human wealth returns implied by the models with human wealth. The benchmark Models $2,3 \& 4$ have slightly worse implications for the two consumption moments. Clearly adding cay and imposing cointegration does not help to fix these models. Our model in the last column matches the consumption moments by construction: We obtain a stronger negative correlation between both current human and financial wealth innovations and news about future innovations than in Table 2. Financial asset return and market return innovations are now also strongly negatively correlated in panel B, which uses stock returns. These results strengthen our conclusion that good news on Wall Street must be Bad news on Main Street.

[Table 6 about here.]

Predictability We checked that our cay measure also forecasts future financial asset returns, both firm value returns and stock returns. In a univariate forecasting regression, the $R^{2}$ goes from $3.5 \%$ at 1 -quarter horizon to $30.2 \%$ at 5 -year horizons in the firm value return equation. The predictability coefficients are statistically significant at the $1 \%$ level at all horizons. For stock returns, the $R^{2}$ even goes up to $49.7 \%$ at the 5 -year horizon. This confirms the findings of Lettau and Ludvigson (2001a). We also computed the actual 
consumption-wealth ratio from the model, and we found that it predicts stock returns with the right $\operatorname{sign}^{14}$.

\subsection{Long-Run Consumption and Market Return Risk}

Finally, the model imposes an additional restriction on the low-frequency properties of consumption and the market return that we have ignored sofar, and this restriction does not depend on the household's preferences.

\subsubsection{Violates Long-Run Restriction}

The household budget constraint (2) and the stationarity of the consumption-wealth ratio imply the following restriction on the long-run effect of news about market returns and consumption growth:

$$
\left(E_{t+1}-E_{t}\right) \sum_{j=0}^{\infty} \rho^{j} r_{t+1+j}^{m}=\left(E_{t+1}-E_{t}\right) \sum_{j=0}^{\infty} \rho^{j} \Delta c_{t+1+j}
$$

In the long run, only cash flows determine the returns on the market -not discount rates. The force of this restriction is that it does not depend on preferences, only on the budget constraint. However, as pointed out by Hansen, Roberds, and Sargent (1991) in a different model, this restriction cannot be exactly satisfied for all possible shocks in the model with constant wealth shares, if the VAR includes labor income growth and consumption growth ${ }^{15}$, but we can test the restriction in the case of time-varying wealth shares. In what follows, only news about future cash flows, labor income growth and dividend growth, matters.

For Model 5, the correlation between $(m)_{t}+\left(h^{m}\right)_{t}$ and $\left(d^{c}\right)_{t}$ is .11 for firm value returns and .12 for stock returns in quarterly data, but the market response is about twice as volatile. This correlation increases to .39 at annual frequencies for firm value returns and .36 for stock returns over the 1947-2004 sample and even .69 for stock returns over the 1930-2004 sample. On the other hand, the correlation is negative in the model without human wealth. Increasing the labor income share $(\bar{s}=\bar{\nu})$ lines up the long-run responses of consumption and the market return even better. This is because, in the data, the long-run

\footnotetext{
${ }^{14}$ Detailed Results available.

${ }^{15}$ It is ruled out by the VAR identification. Appendix A.2.6 explains the details of this argument. So, for the models with constant wealth shares, we cannot test the long-run restriction, because of the linearity, but we can test it in the case of time-varying wealth shares. The reason is that both $(m)_{t}+\left(h^{m}\right)_{t}$ and $\left(d^{c}\right)_{t}$ are quadratic, not linear, functions of the innovations $\varepsilon_{t}$ (see appendix A.2.6).
} 
responses of labor income and consumption growth are more similar. Putting more weight (higher $\bar{\nu}$ ) on the cash-flow news of human wealth brings the left-hand side of the long-run restriction closer to the right-hand side, cash-flow news in consumption.

So, bringing in human wealth delivers a much better measure of long run risk. Still we do not completely eliminate the excess volatility of market returns in the long run. A resolution of this long-run volatility puzzle and formal testing of the restriction is left for future work.

\subsubsection{Backing out Human Wealth Returns}

Instead of using labor income growth data in the VAR, one way around the violation of the long-run restriction is to back out news about current and future labor income growth $\left(d^{y}\right)$ from the long-run restriction itself, using consumption and financial returns data:

$$
\left(d^{y}\right)_{t+1}=\frac{1}{\bar{\nu}}\left(d^{c}\right)_{t+1}-\frac{1-\bar{\nu}}{\bar{\nu}}\left(d^{a}\right)_{t+1} .
$$

This way the long-run restriction is satisfied by construction. Simply imposing this restriction turns out to reduce the distance between the Shiller (Model 3) and JW (Model 4 ) benchmark models with human wealth and our reverse-engineered model (Model 5). Section A.4 in the separate appendix takes a closer look at this new measure of human wealth cash flow news, $d^{y}$.

The first three columns of each panel of Table 7 display the results for the three benchmark models of human wealth; panel A reports the results using firm value returns, panel B reports the results for stock returns. Remarkably, for Models 3844 , the model-implied variance of consumption dropped to only 1.5 and 1.3, compared to 0.3 in the data, while the correlation with financial asset return innovations falls by half relative to Table 2 for all three models. The reason for this dramatic improvement is that the increased meanreversion in market returns, especially in Models $3 \mathscr{E} 4$ (last row). Financial and human wealth returns are negatively correlated for these two models, whereas before, using the $d^{y}$ extracted from labor income growth data, they were not. This feature is a critical ingredient to generating consumption innovations that are smooth and not too correlated with financial return innovations. Indeed, in the last column, our reverse engineered human wealth return is negatively correlated with financial wealth returns. Comparing column Reverse to column Model 4, we see that they are much more similar than in our previous exercise in Table 2. In short, because $\operatorname{Corr}_{d^{y}, a}<0$ for firm value returns, we need 
less of a counter-acting effect from human wealth discount rates; $\operatorname{Corr}_{h^{y}, a}$ is moderately positive. Model 4 implies such correlation. The reduced reliance on the discount rate channel is reassuring, because the discount rates channel is to some extent a measure of our ignorance.

The results using stock returns, reported in panel B, are quite different (see section A.4 in the separate appendix for a complete discussion). In this case, Models $3 \& 4$ actually do worse than before, and the importance of the discount rate channel in the matching exercise increases. Clearly, especially for long-run risk, the precise measurement of financial returns is critically important. This deserves further study.

[Table 7 about here.]

To conclude, in this section we used the long-run restriction to back out (permanent) cash-flow effects of human wealth $\left(d^{y}\right)$, and we used the short-run variance and correlation moments to back out the (temporary) discount rate effects $\left(h^{y}\right)$. We found even stronger evidence that the returns on human and financial wealth must be negatively correlated than in section 5 , but at least for the broad measure of financial returns, imposing this long-run restriction helps to close the gap between the benchmark models and the reverse-engineered model.

\section{The Consumption-Consistent CAPM}

This section examines the time-series and cross-sectional asset pricing implications of using model-implied market return and consumption instead of actual consumption: For each model, we impose additional discipline by insisting on using the consumption innovations implied by the model. Only in our reverse-engineered model does the model-implied consumption series coincide exactly with actual consumption in the data.

\subsection{Time-Series Properties of the SDF}

A logical first question is whether the models we considered can price a broad stock market return and a risk-free rate. Each of these models implies a different time series for consumption innovations and the market return, and hence a different stochastic discount factor $M$ :

$$
M_{t+1}=\exp \left(\theta \log \beta-\frac{\theta}{\sigma} \Delta c_{t+1}+(\theta-1) r_{t+1}^{m}\right)
$$


We compute the stochastic discount factor for each model and study the moments of the Euler equation errors for asset $i$

$$
\operatorname{error}_{t+1}^{i}=M_{t+1} \exp \left(r_{t+1}^{i}\right)-1
$$

where $r^{i}$ is either the real log gross return on the value-weighted CRSP stock market portfolio $\left(r^{s}\right)$ or the real log gross return on a 3-month T-bill $\left(r^{f}\right)$. Table 8 compares Euler equation errors across the different models presented in the previous section. The first column is Model 1, the model with financial wealth only $\nu_{t}=0$. The market return is simply the financial asset return. The second and third columns are Model 2 without and with time-varying human wealth share. Columns four and five report Model 3 without and with time-varying human wealth share. Likewise, columns six and seven are for Model 4 model, and the last two columns are for our model. Column 8 is our model with constant human wealth shares (labeled Reverse): here we use actual consumption data to back out a process for $h^{y} \cdot{ }^{16}$ For our model with time-varying wealth shares (last column), we choose the optimal vector $C$ to match the variance of consumption innovations, the correlation of consumption innovations with financial asset return innovations, as well as the correlation between consumption innovations in the model and in the data. ${ }^{17}$

In all models, we used the broader financial return measure, the firm value return, to compute the market return, and we consider two values for the $E I S: \sigma=.28$ (our benchmark) and $\sigma=1.12$ (the value proposed by Vissing-Jorgensen and Attanasio (2003)). For each of these models, we find the value for $\gamma$ that minimizes the root mean squared pricing error on the stock return and the risk-free rate. This value is reported in the first row of table 8. Clearly, consumption growth is most volatile in Model 1 without human wealth and least volatile in model Reverse. Not surprisingly, the value for $\gamma$ is highest in our two models (last two columns) than in Model 1. In the reverse-engineered model (Reverse), consumption growth is identical to observed consumption growth, and the market return process, is the one implied by actual consumption. For that model, we find $\gamma=23.09$. The return on stocks is predicted to be 28 basis points too high; i.e. $2.54 \%$ per quarter

\footnotetext{
${ }^{16}$ In this procedure, we back out $h^{y}$ from consumption data (equation 20). We form innovations in current human wealth returns from $y=d^{y}-h^{y}$. To form realized market returns $r^{m}=(1-\nu) r^{a}+\nu r^{y}$, we need realized human wealth returns $r^{y}$. Realized human wealth returns are the sum of innovations in current human wealth returns $y$ and expected human wealth returns. Since this procedure does not identify expected human wealth returns, we assume that they are the same as in Model 4 , the model the closest to ours. This choice does not affect the RMSE in column 7.

${ }^{17}$ The matching exercise is successful in that it yields a model-implied consumption growth process that has a correlation of 0.87 with consumption growth in the data (see last but one row). The downside is that consumption is now 3 times too volatile.
} 
instead of the observed $2.26 \%$ per quarter. The risk-free rate is predicted to be 21 basis points too low; i.e. $0.00 \%$ per quarter instead of $0.21 \%$ per quarter. While our model certainly makes progress on the equity premium and the risk-free rate puzzle, it does not completely resolve it. For comparison, the pricing errors in Campbell's model (Model 2 in first column) are less than half the size, but this superior performance comes from the fact that consumption growth in that model is 5 times too volatile and only weakly correlated with consumption growth in the data.

In the case of a high EIS, the pricing errors are mostly much larger, except for Model 5 , the model with time-varying wealth shares and human wealth discount rates chosen to match the actual consumption data as close as possible. It predicts an expected stock return that is 67 basis points too low and a risk-free rate that is 66 basis points too high. So it comes reasonably close to matching the risk-free rate and the equity premium for $\gamma$ of only 4. But, as will become apparent in the next section, this model with its mean-averting market return for $\sigma>1$, will fail in pricing a broader cross-section of assets.

[Table 8 about here.]

\subsection{Cross-Section of Size and Value Portfolios}

We start from the linearized Euler equation for asset $i$ :

$$
\begin{aligned}
E_{t} r_{t+1}^{i}-r_{t}^{f}+\frac{V_{i i}}{2} & =\frac{\theta}{\sigma} V_{i c}+(1-\theta) V_{i m} \\
& =\gamma V_{i m}+(\gamma-1) V_{i h^{m}}
\end{aligned}
$$

In an Epstein-Zin asset pricing model, the expected excess return (corrected for one-half its variance) is determined by two risk factors: the covariance of return $i$ with aggregate consumption growth $V_{i c}$ and the covariance of return $i$ with the market return $V_{i m}$ (equation 27). Campbell (1993) substitutes out consumption, replacing $V_{i c}$ by $V_{i m}+(1-\sigma) V_{i h^{m}}$, which leads to asset pricing equation (27). We have argued that the consumption processes in the three canonical models are very different from the observed consumption process. This will lead to a market return process, different from the one in our consumptionconsistent model. Therefore, we stay with equation (26), and evaluate the performance of the three canonical models and our model in pricing the cross-section of stock returns.

Taking unconditional expectations of (26) delivers an unconditional asset pricing equa-

tion. Following Campbell, we define the excess returns on $I$ assets $e r_{t+1}^{i}=r_{t+1}^{i}-r_{t}^{f}$ with unconditional means $\mu_{i}$. Both vectors have dimension $I \times 1$. We define demeaned 
returns $\eta_{t+1}^{i} \equiv e r_{t+1}^{i}-\mu^{i}$. We estimate the market prices of risk, $\lambda_{k}$ off the ex-post version of equation (26). The factor risk prices $\lambda_{c}$ and $\lambda_{m}$ depend on the coefficient of relative risk aversion $\gamma$ and the intertemporal elasticity of substitution $\sigma$. We implement a FamaMacBeth procedure (Fama and MacBeth (1973)): in the first stage we estimate the factor loadings $\beta_{i c}$ and $\beta_{i m}$ for each of the 25 size and value portfolios from a time-series regression of the log excess returns on model-implied consumption growth and market return. In the second stage, we estimate the market prices of risk from a cross-sectional regression of variance-adjusted mean log excess returns on the factor betas from the first stage.

[Table 9 about here.]

The first two columns of Table 9 show the expected return and the expected return with a variance correction for the 25 size and book-to-market decile portfolios (quarterly data for 1947.II-2004.III from Kenneth French). Low book-to-market (growth) firms have lower average returns than high book-to-market (value) firms and small firms have higher average returns than large firms. The next two columns report our model's predicted adjusted return and the pricing error; the part of the return that is not explained by sample covariances with the factors and the sample estimates of the risk prices. The last three columns report the risk contribution to the expected excess return of each asset; the first one of which is the market price of risk on a constant $\left(\lambda_{0}, \lambda_{c} \times \beta_{i c}\right.$ and $\left.\lambda_{m} \times \beta_{i m}\right)$. We use the consumption measure and the market return measure of our model with timevarying human wealth share and the optimal vector $C$, i.e. the one that is consistent with aggregate consumption moments, for $\sigma$ equal to .28. In all models, the financial asset return is the firm value return.

Our model does a reasonable job accounting for the value spread. In each size quintile, growth firms (B1) are predicted to give a lower average return than value firms (B5), and just as in the data, the value effect is stronger for small firms. To measure the pure value effect, we use book-to-market decile returns instead. Our model predicts a value spread of $1.1 \%$ per quarter, whereas in the data the spread is $1.4 \%$.

There is an interesting cross-sectional pattern in the betas of the book-to-market decile returns with $\beta_{i m}$ and $\beta_{i h}$. The top panel of figure 7 shows that growth firms are more exposed to consumption risk than value firms (the second number in the horizontal axis index denotes the book-to-market quintile, 11 is small growth, 15 is small value). The bottom panel shows that growth firms form a better hedge against future market risk than value firms. This is confirmed in the last two columns of Table 9, which show that the risk 
contribution of the market factor is much lower for growth firms than for value firms.

[Figure 7 about here.]

For the low EIS case, Panel A in table 10 compares the estimates for the market prices of risk and their standard errors, the root mean-squared pricing error and the cross-section $R^{2}$ from the second stage of the Fama-MacBeth procedure across models. Each of the nine columns denotes a different model, each with a different implied consumption growth and market return process. These are the same models as in Table 8 .

[Table 10 about here.]

The market price of risk on the market return is positive and significant in our model, but it is negative in the model without human wealth and the three benchmark models with human wealth: 12 in Model 5 versus -2.2, -3.1, -.7, and -.7 in columns Model 1, Model 2, Model 3, and Model 4 respectively. Our models (last two columns) are the only one that deliver positive market prices of risk on both risk factors ${ }^{18}$. All other models imply that growth firms are exposed to more market risk than value firms, whereas the opposite is true when the market return is consistent with consumption data. Among the models with constant wealth shares, our model (column 8) has the lowest root mean-squared pricing error (RMSE is $0.7 \%$ per quarter) and the highest cross-sectional $R^{2}(65 \%)$. Among the models with time-varying wealth shares, our model also delivers the lowest RMSE. Model 4, whose market return process shares many of the features of our market return process, also prices the 25 Fama-French portfolios reasonably well $\left(R^{2}=45 \%\right)$. One failure of all models, is that the intercept $\lambda_{0}$ remains statistically different from zero.

The second panel in table 10 shows the asset pricing results for $\sigma=1.12$, the value of the EIS estimated by Vissing-Jorgensen and Attanasio (2003) for stockholders. The market price of risk is no longer significant for Model 5 (last two columns) and the $R^{2}$ is much lower. While this model almost matched the risk-free rate and the equity premium, it cannot explain any of the cross-sectional variation in asset returns.

We conclude that the omission of human wealth returns in the calculation of the market return is significant for the CAPM's ability to explain the cross-section of stock returns. When human wealth returns are made consistent with observed consumption, an interesting pattern arises in firm's exposures to market returns: growth firms have lower risk premia because they provide a better hedge against market risk, and human capital risk is priced.

\footnotetext{
${ }^{18}$ The market price of consumption risk should be positive according to the theory if $\gamma>1$, because $1 / \sigma>1$.
} 


\section{Other Explanations}

The previous analysis attributed to human wealth returns the part of consumption innovations that could not be explained by financial wealth return innovations. In this section, we consider four potential explanations for the lack of correlation and the volatility puzzle. All four are richer versions of Model 1 with financial wealth only. We find that the usual fixes tend to make the puzzles worse, rather than better.

First, we consider heteroscedastic returns on financial assets and heteroscedastic consumption growth, and we develop a way of testing whether this effect drives our results. We find it does not. Second, we consider the effect of habit-style preferences. Standard habits can be ruled out because they cannot lower the correlation between consumption innovations and returns. Third, we consider heterogeneity across households, and we argue reasonable specifications of heterogeneity only make the puzzle worse. Fourth, we briefly consider consumption adjustment costs as a potential explanation.

Finally, we address a potential criticism of a different nature; that the human wealth return residual proxies for housing wealth. When we add housing wealth to the model, we find our residual has much the same properties as in the model without housing wealth.

\subsection{Heteroscedastic Market Returns}

Sofar we have abstracted from time-variation in the joint distribution of consumption growth and returns. Recently, Duffee (2005) reported finding some evidence of timevariation in the covariance between stock returns and consumption growth. We denote the conditional variance term by $\mu_{t}^{m}$. This adds a third source of consumption innovations ( see equation (38) in Campbell (1993)), which reflects the influence of changing risk on the household's saving decisions:

$$
\begin{array}{r}
c_{t+1}-E_{t} c_{t+1}=r_{t+1}^{m}-E_{t} r_{t+1}^{m}+(1-\sigma)\left(E_{t+1}-E_{t}\right) \sum_{j=1}^{\infty} \rho^{j} r_{t+1+j}^{m} \\
-\left(E_{t+1}-E_{t}\right) \sum_{j=1}^{\infty} \rho^{j} \mu_{t+1+j}^{m},
\end{array}
$$

where $\mu_{t}^{m}=\sigma \log \beta+.5\left(\frac{\theta}{\sigma}\right) \operatorname{Var}_{t}\left[\Delta c_{t+1}-\sigma r_{t+1}^{m}\right]$. This last term drops out if either $\gamma$ or $\sigma$ are one. We refer to this last term as news about future variances, $h^{\mu 19}$. If this time-variation

\footnotetext{
${ }^{19}$ Assume we are in the plausible parameter range: $\gamma>1$ and $\sigma<1$. In this case, the last term can only resolve the correlation puzzle if $V_{m, h^{\mu}}$ is strongly positive -good news in the stock market today persistently increases the conditional volatility of future financial returns or consumption innovations or decreases their
} 
plays a role, our consumption growth accounting residual should predict the future variance of stock market returns, and/or the future variance of consumption and/or the conditional covariance between the two. So, we check whether the residual $\left(h^{y}\right)_{t}$ that comes out of our model with time-varying human wealth shares predicts $\operatorname{Var}_{t}\left[\Delta c_{t+1}-\sigma r_{t+1}^{m}\right]$. We find that it does not.

More precisely, from the VAR innovations, we construct the implied conditional moments of financial asset returns and consumption growth:

$$
\begin{aligned}
V_{t}^{a} \equiv V_{t}\left[r_{t+1}^{a}\right] & =e_{1}^{\prime} A z_{t} z_{t}^{\prime} A^{\prime} e_{1}+e_{1}^{\prime} \Sigma e_{1}, \\
V_{t}^{c} \equiv V_{t}\left[\Delta c_{t+1}\right] & =e_{7}^{\prime} A z_{t} z_{t}^{\prime} A^{\prime} e_{7}+e_{7}^{\prime} \Sigma e_{7}, \\
V_{t}^{a, c} \equiv C \operatorname{Cov}_{t}\left[\Delta c_{t+1}, r_{t+1}^{a}\right] & =e_{1}^{\prime} A z_{t} z_{t}^{\prime} A^{\prime} e_{7}+e_{1}^{\prime} \Sigma e_{7} .
\end{aligned}
$$

Next, we regress $\operatorname{Var}_{t}\left[\Delta c_{t+1}-\sigma r_{t+1}^{m}\right]=\sum_{j=1}^{H} \rho^{h}\left(V_{t+j}^{c}+\sigma^{2} V_{t+j}^{a}-2 \sigma V_{t+j}^{c, a}\right)$ on $\left(h^{y}\right)_{t}$. We vary $j$ from 1 to 24 quarters. Using firm value returns, the regression coefficient is never statistically significant (we use Newey-West standard errors), and the $R^{2}$ of the regression never exceeds 1\%. We only find statistical significance at the $10 \%$ level for $\sigma=.28$ when financial asset returns are stock returns and only for horizons beyond 12 quarters. However, the $R^{2}$ never exceeds $3 \%$, and the marginal significance disappears for higher $\sigma$. We conclude that there is very weak evidence that our residual proxies for heteroscedasticity in returns and consumption growth.

\subsection{Habits}

Second, we consider the possibility that habit formation in the household's preferences is responsible for the discrepancy between consumption innovation moments in the model and the data. If the $\log$ surplus consumption ratio follows an $\operatorname{AR}(1)$ with coefficient $0<\phi<1$ and a constant sensitivity parameter $\lambda>0$ that multiplies the consumption growth innovations ${ }^{20}$, then news about consumption is given by:

$$
c_{t+1}-E_{t} c_{t+1}=\left[\frac{1-\phi \rho}{1-\phi \rho+\lambda \rho(\phi-1)}\right]\left\{\begin{array}{c}
\left(r_{m, t+1}-E_{t} r_{m, t+1}\right)+ \\
(1-\sigma)\left(E_{t+1}-E_{t}\right) \sum_{j=1} \rho^{j} r_{m, t+j+1}
\end{array}\right\}
$$

See section A.5 of the separate appendix for the derivation. Clearly, the habit cannot fix the volatility and correlation puzzles because, when $\phi<1$, the term in brackets is larger

${ }^{20}$ We fix the sensitivity parameter, because we just checked for heteroscedasticity in section 7.1. 
than 1. Rather, the puzzle in a model with habits is even larger.

\subsection{Heterogeneity}

Finally, allowing for heterogeneity across agents might even make these puzzles worse. When households have the same EIS, aggregation reproduces exactly equation (4) for aggregate consumption innovations under fairly mild conditions, described in section A.6 of the separate appendix, and all of the previous results go through trivially. However, if household wealth and the EIS are positively correlated, then the aggregate EIS that shows up in the aggregate consumption innovation expression exceeds the average EIS across households. In fact, Vissing-Jorgenson (2002) reports evidence of a higher EIS for wealthier stock- and bond-holders. A higher aggregate IES worsens the consumption volatility and correlation puzzles.

Two Agents To illustrate this with a simple example, consider an economy with two agents. Both face the same aggregate state variables. The first agent holds all human wealth, and the second agent holds all financial wealth. We compute the model-implied consumption innovations for each. Aggregate consumption innovations are the weighted sum of the two individual innovations, weighted by the wealth shares. For comparison with table 2 , we hold the human wealth share fixed at .70. If both agents have a $\sigma=.28$, the aggregate consumption moments for the benchmark models are exactly as reported in rows 8 and 9 of table 2 . If instead the financial wealth holder has a higher EIS, his consumption innovations are more volatile and more highly correlated with financial asset returns, and so are the aggregates. For $\sigma=1.1$, the value estimated by Vissing-Jorgenson (2002) for stock holders, the volatility of aggregate consumption innovations is $41 \%, 29 \%$ and $28 \%$ higher in Models 2, 3, \& 4 than in the case where both agents have $\sigma=.28 .^{21}$ The correlation between aggregate consumption innovations and financial asset returns are .87, .93 and .94; the latter two are again higher than in the homogeneity case. This argument readily extends to more households and to households with both financial and human wealth. If the EIS and ratio of financial wealth to total wealth are positively correlated, the consumption puzzles will be worse than in the economy with a stand-in agent with the average EIS.

\footnotetext{
${ }^{21}$ In the data, financial wealth holders' consumption is more volatile than average consumption, but not nearly as high as in the model. Vissing-Jorgenson (2002) finds a $6 \%$ consumption growth volatility for stock holders, compared to a $3.4 \%$ volatility for all households. However, the model-implied volatility of consumption growth for the agent with only financial wealth and $\sigma=1.1$ is $15 \%$ per year!
} 
Borrowing Constraints What about borrowing constraints? Binding constraints add a third component to aggregate consumption innovations, news about future average multipliers on these constraints:

$c_{t+1}-E_{t} c_{t+1}=r_{t+1}^{m}-E_{t} r_{t+1}^{m}+(1-\sigma)\left(E_{t+1}-E_{t}\right) \sum_{j=1}^{\infty} \rho^{j} r_{t+1+j}^{m}-\left(E_{t+1}-E_{t}\right) \sum_{j=1}^{\infty} \rho^{j} \lambda_{t+1+j}$,

where $\lambda_{t+j}$ denotes the cross-sectional weighted-average multiplier at $t+j$ (see section A.7 of the separate appendix for a derivation). Clearly, it does not help to have very binding constraints all the time. For model-implied consumption innovations to be smooth and only mildly correlated with financial asset returns, a positive innovation in financial returns must be associated with more binding constraints in the future. The collateral constraints of Lustig and VanNieuwerburgh (2004) have this feature.

Consumer Inattentiveness Finally, Gabaix and Laibson (2002) and Reis (2004), among others, have argued that rational consumers may only periodically re-optimize, if it costly to process the information required to do so. In that case, equation (4) only applies to those consumers who are currently adjusting. To address this concern, we have re-done the entire exercise on annual and bi-annual data, only to find identical results (detailed results available upon request). It seems very likely that the effects of information processing costs would be gone after a couple of quarters, especially because households face a lot of large, idiosyncratic shocks that would cause them to adjust, even if the aggregate shocks themselves are small (e.g. Golosov and Lucas (2003) for a similar argument applied to costly price adjustment for firms).

\subsection{Housing Wealth}

As a last robustness check, we include a third source of wealth besides financial wealth and human wealth: housing wealth. Consumption $c$ is now non-durable and services consumption excluding housing services. The stand-in consumer has non-separable preferences over $c$ and housing consumption; we fix the intra-temporal elasticity of substitution at .5 , taken from Yogo (2005), but our results are quite robust. We solve the model with constant and time-varying human wealth shares. Section A.8 in the separate appendix describes the derivation and data in more detail. We find that the human wealth 'residual' does not proxy for housing wealth. Rather, the properties of consumption-consistent human wealth returns look very similar in the models with and without housing wealth. Our main 
conclusions go through.

\section{Discussion}

From the perspective of a standard, neoclassical growth model, the volatility of consumption innovations relative to that of return innovations and their correlation with return innovations are much too small, even if the representative agent is very reluctant to substitute consumption over time. We propose that the resolution of these puzzles lies in the measurement of human wealth returns. The returns on human wealth need to be negatively correlated with returns on financial assets in order to generate a consumption process that is consistent with the data. This reflects negative correlation in news about the future discount rates and the cash flows for these two assets.

A key question remains: what drives this negative correlation? The two tree models of Santos and Veronesi (2004) and Cochrane, Longstaff, and Santa-Clara (2004) generate a negative correlation between the two discount rates, but an open question is which model can account for the negative correlation between the cash-flows on the two trees. There is some evidence that the current labor market conditions have persistent effects on how workers and owners split the pie (Lustig, VanNieuwerburgh, and Syverson (2005)). This is an important avenue for future research.

\section{References}

Andersen, T., T. Bollerslev, F. Diebold, and C. Vega, 2005, "Real-Time Price Discovery in Stocks, Bonds and Foreign Exchange Markets," Working paper Northwestern University.

Bansal, R., and A. Yaron, 2004, "Risks for the Long Run: A Potential Resolution of Asset Prizing Puzzles," The Journal of Finance, 59, 1481-1509.

Baxter, M., and U. Jermann, 1997, "The International Diversificantion Puzzle is Worse Than You Think," American Economic Review, 87(1), 170-180.

Benzoni, L., P. Collin-Dufresne, and R. Goldstein, 2004, "Portfolio Choice over the Life Cycle in the Presence of ‘Trickle Down' Labor Income," University of Minnesota.

Black, F., 1987, Business Cycles and Equilibrium, Blackwell, Cambridge, MA.

Bottazzi, L., P. A. Pesenti, and E. VanWincoop, 1996, "Wages, Profits and the International Portfolio Puzzle," European Economic Review, 40, 219-254.

Boudoukh, J., R. Michaely, M. Richardson, and M. Roberts, 2004, "On the Importance of Measuring Payout Yield: Implications for Empirical Asset Pricing," NBER Working Paper, 10651. 
Boyd, J. H., J. Hu, and R. Jagannathan, 2005, "The Stock Market's Reaction to Unemployment News: 'Why Bad News is Usually Good for Stocks," Journal of Finance, 60(2), 649 - 672.

Breeden, D. T., 1979, "An Intertemporal Asset Pricing Model with Stochastic Consumption and Investment Opportunities," Journal of Financial Economics, 7, 265-296.

Browning, M., L. P. Hansen, and J. J. Heckman, 2000, "Micro Data and General Equilibrium Models," in John Taylor, and Mark Woodford (ed.), Handbook of Macroeconomics, North Holland, Amsterdam.

Campbell, J. Y., 1991, "A Variance Decomposition for Stock Returns," Economic Journal, 101, $157-179$.

Campbell, J. Y., 1993, "Intertemporal Asset Pricing Without Consumption Data," American Economic Review, 83(3), 487-511.

Campbell, J. Y., 1996, "Understanding Risk and Return," The Journal of Political Economy, 104, $298-345$.

Campbell, J. Y., and J. H. Cochrane, 1999, "By Force of Habit: A Consumption-Based Explanation of Aggregate Stock Market Behavior.," Journal of Political Economy, 107, 205-251.

Cochrane, J. H., 1994, "Permanent and Transitory Components of GNP and Stock Prices," The Quarterly Journal of Economics, 109, 241-265.

Cochrane, J. H., F. Longstaff, and P. Santa-Clara, 2004, "Two Trees," Working Paper UCLA Anderson School of Management.

Duffee, G. R., 2005, "Time-Variation in the Covariation Between Consumption Growth and Stock Returns," Journal of Finance.

Epstein, L. G., and S. Zin, 1989, "Substitution, Risk Aversion and the Temporal Behavior of Consumption and Asset Returns: A Theoretical Framework," Econometrica, 57, 937-969.

Fama, E., and K. French, 2001, "Disappearing Dividends: Changing Firm Characteristics or Lower Propsensity to Pay?," Journal of Financial Economics, 60,, 3-43.

Fama, E. F., and J. D. MacBeth, 1973, "Risk, Return, and Equilibrium: Empirical Tests," The Journal of Political Economy, 81, 607-636.

Gabaix, X., and D. Laibson, 2002, "The 6D Bias and the Equity Premium Puzzle," NBER Macroeconomics Annual, pp. 257-312.

Golosov, M., and R. E. Lucas, 2003, "Menu Costs and Phillips Curves," NBER Working Paper, 10187.

Grossman, S., and R. Shiller, 1981, "The Determinants of the Variability of Stock Market Prices," American Economic Review, 71, 222-227. 
Grullon, G., and R. Michaely, 2002, "Dividends, Share Repurschases and the Susbstitution Hypothesis," Journal of Finance, 62, 1649-84.

Guvenen, F., 2003, "A Parsimonious Macroeconomic Model for Asset Pricing: Habit Formation or Cross-Sectional Heterogeneity," Working Paper University of Rochester.

Hall, R. E., 1988, "Intertemporal Substitution in Consumption," Journal of Political Economy, 96, $339-357$.

Hall, R. E., 2001, "The Stock Market and Capital Accumulation," American Economic Review, 91, $1185-1202$.

Hansen, L. P., J. C. Heaton, and N. Li, 2005, "Consumption Strikes Back," Working Paper University of Chicago.

Hansen, L. P., W. Roberds, and T. J. Sargent, 1991, "Time-Series Implications of Present Value Budget Balance and Martingale Models of Consumption and Taxes," in Lars P. Hansen, and Thomas J. Sargent (ed.), Rational Expectations Econometrics, Westview Press.

Hansen, L. P., and K. Singleton, 1983, "Stochastic Consumption, Risk Aversion, and the Temporal Behavior of Asset Returns," Journal of Political Economy, 91, 249-265.

Heaton, J., and D. Lucas, 1996, "Evaluating the Effects of Incomplete Markets on Risk Sharing and Asset Pricing," Journal of Political Economy, 104, 668-712.

Jagannathan, R., and Z. Wang, 1996, "The Conditional CAPM and the Cross-Section of Expected Returns," The Journal of Finance, 51, 3-53.

Julliard, C., 2003, "The Internal Diversification Puzzle is Not Worse Than You Think," International Finance, 0301004.

Kandel, S., and R. F. Stambaugh, 1990, "Expectations and Volatility of Consumption and Asset Returns," Review of Financial Studies, 3, 207-232.

LeRoy, S. F., and R. D. Porter, 1981, "The Present-Value Relation: Tests Based on Implied Variance Bounds," Econometrica, 49, 555-574.

Lettau, M., and S. Ludvigson, 2001a, "Consumption, Aggregate Wealth and Expected Stock Returns," The Journal of Finance, 56, 815-849.

Lettau, M., and S. Ludvigson, 2001b, "Resurrecting the (C)CAPM: A Cross-Sectional Test When Risk Premia Are Time-Varying," The Journal of Political Economy, 109, 1238-1287.

Lewellen, J., and S. Nagel, 2004, "The Conditional CAPM Does Not Explain Asset Pricing Anomalies," Working Paper MIT Sloan.

Lucas, R., 1978, "Asset Prices in an Exchange Economy," Econometrica, 46, 1429-54.

Lustig, H., and S. VanNieuwerburgh, 2004, "A Theory of Housing Collateral, Consumption Insurance and Risk Premia," Working Paper NYU Stern and University of Chicago. 
Lustig, H., S. VanNieuwerburgh, and C. Syverson, 2005, "Equilibrium Search in the Labor Market and the Value of the Capital Stock," Working Paper.

Mehra, and E. Prescott, 1985, "The Equity Premium: A Puzzle.," Journal of Monetary Economics, $15,145-161$.

Mulligan, C., 2004, "Robust Implications of Aggregate Stochastic Discount Factor Volatility," Working Paper University of Chicago.

Palacios-Huerta, I., 2001, "The Human Capital of Stockholders and the International Diversification Puzzle," Journal of International Economics, 54, 309-331.

Palacios-Huerta, I., 2003a, "An Empirical Analysis of the Risk Properties of Human Capital Returns," American Economic Review, 93, 948-964.

Palacios-Huerta, I., 2003b, "The Robustness of the Conditional CAPM with Human Capital," Journal of Financial Econometrics, 1, 272-289.

Reis, R., 2004, "Inattentive Consumers," Working Paper Princeton University.

Roll, R., 1977, "A Critique of the Asset Pricing Theory's Tests," Journal of Financial Economics, 4, 129-176.

Santos, T., and P. Veronesi, 2004, "Labor Income and Predictable Stock Returns," Review of Financial Studies, forthcoming.

Shiller, R. J., 1981, "The Use of Volatility Measures in Assessing Market Efficiency," Journal of Finance, 36, 291-304.

Shiller, R. J., 1995, "Aggregate Income Risks and Hedging Mechanisms," Quarterly Review of Economics and Finance.

Stambaugh, R. F., 1982, "On The Exclusion of Assets From the Two Parameter Model: A Sensitivity Analysis," Journal of Financial Economics, 10, 237-268.

Tallarini, T., 2000, "Risk-Sensitive Real Business Cycles," Journal of Monetary Economics, 45(3), $507-532$.

Vissing-Jorgensen, A., and O. P. Attanasio, 2003, "Stock-Market Participation, Intertemporal Substitution and Risk Aversion," American Economic Review Papers and Proceedings, 93, 383-391.

Vissing-Jorgenson, A., 2002, "Limited Asset market Participation and Elasticity of Intertemporal Substitution," The Journal of Political Economy, 110, 825-853.

Yogo, M., 2005, "A Consumption-Based Explanation of the Cross-Section of Expected Stock Returns," forthcoming Journal of Finance.

Young, A. T., 2004, "Labor's Share Fluctuations, Biased Technical Change, and the Business Cycle," Review of Economic Dynamics, 7, 916-931. 


\section{A Appendix}

\section{A.1 Data Appendix: Returns on Firm Value}

This computation is based on Hall (2001). The data to construct our measure of returns on firm value were obtained from the Federal Flow of Funds (Federal Reserve Board of Governors, downloadable at www.federalreserve.gov/ releases/z1/current/data.htm). The data are for nonfarm, non-financial business. We extracted the stock data from ltabs.zip. The Coded Tables provide more information about the codes used in the Flow of Funds accounts. A complete description is available in the Guide to the Flow of Funds Accounts. We calculated the value of all securities as the sum of financial liabilities (144190005), the market value of equity (1031640030) less financial assets (144090005), adjusted for the difference between market and book for bonds. The subcategories unidentified miscellaneous assets (113193005) and liabilities (103193005) were omitted from all of the calculations. These are residual values that do not correspond to any financial assets or liabilities. We correct for changes in the market value of outstanding bonds by applying the index of corporate bonds to the level of outstanding corporate bonds at the end of the previous year. The Dow Jones Corporate Bond Index is available from Global Financial Data. We measured the flow of pay-outs as the flow of dividends (10612005) plus the interest paid on debt (net interest series from NIPA, see Gross Product of non-financial,corporate business.) less the increase in the volume of financial liabilities (10419005), which includes issues of equity (103164003).

\section{A.2 Notation and Model Details}

$$
\begin{aligned}
V_{a} & =V\left[r_{t+1}^{a}-E_{t}\left[r_{t+1}^{a}\right]\right] \\
V_{d^{y}} & =V\left[\left(E_{t+1}-E_{t}\right) \sum_{j=0}^{\infty} \rho^{j} \Delta y_{t+1+j}\right] \\
V_{h}^{a} & =V\left[\left(E_{t+1}-E_{t}\right) \sum_{j=1}^{\infty} \rho^{j} r_{t+1+j}^{a}\right] \\
\operatorname{Corr}_{a, h^{a}} & =\operatorname{Corr}\left[r_{t+1}^{a}-E_{t}\left[r_{t+1}^{a}\right],\left(E_{t+1}-E_{t}\right) \sum_{j=1}^{\infty} \rho^{j} r_{t+1+j}^{a}\right] \\
\operatorname{Corr}_{a, d^{y}} & =\operatorname{Corr}\left[r_{t+1}^{a}-E_{t}\left[r_{t+1}^{a}\right],\left(E_{t+1}-E_{t}\right) \sum_{j=0}^{\infty} \rho^{j} \Delta y_{t+1+j}\right] \\
\operatorname{Corr}_{h^{a}, d^{y}} & =\operatorname{Corr}\left[\left(E_{t+1}-E_{t}\right) \sum_{j=0}^{\infty} \rho^{j} \Delta y_{t+1+j},\left(E_{t+1}-E_{t}\right) \sum_{j=1}^{\infty} \rho^{j} r_{t+1+j}^{a}\right]
\end{aligned}
$$

News to future expected returns on human wealth, $\left(h^{y}\right)_{t}$, is an unobservable to the econome- 
trician. The following moments of $\left(h^{y}\right)_{t}$ will play a crucial role in the exercise:

$$
\begin{aligned}
V_{h^{y}} & =V\left[\left(E_{t+1}-E_{t}\right) \sum_{j=1}^{\infty} \rho^{j} r_{t+1+j}^{y}\right] \\
\operatorname{Corr}_{a, h^{y}} & =\operatorname{Corr}\left[r_{t+1}^{a}-E_{t}\left[r_{t+1}^{a}\right],\left(E_{t+1}-E_{t}\right) \sum_{j=1}^{\infty} \rho^{j} r_{t+1+j}^{y}\right] \\
\operatorname{Corr}_{d^{y}, h^{y}} & =\operatorname{Corr}\left[\left(E_{t+1}-E_{t}\right) \sum_{j=0}^{\infty} \rho^{j} \Delta y_{t+1+j},\left(E_{t+1}-E_{t}\right) \sum_{j=1}^{\infty} \rho^{j} r_{t+1+j}^{y}\right. \\
\operatorname{Corr}_{h^{a}, h^{y}} & =\operatorname{Corr}\left[\left(E_{t+1}-E_{t}\right) \sum_{j=1}^{\infty} \rho^{j} r_{t+1+j}^{a},\left(E_{t+1}-E_{t}\right) \sum_{j=1}^{\infty} \rho^{j} r_{t+1+j}^{y}\right]
\end{aligned}
$$

\section{A.2.1 Moments of Consumption Innovations with Constant Wealth Shares}

We denote the innovations to current consumption growth using $(c)_{t}$. Using the symbols defined in the text, we get:

$$
(c)_{t}=(1-\bar{\nu})(a)_{t}+\bar{\nu}\left(d^{y}\right)_{t}+(1-\sigma)(1-\bar{\nu})\left(h^{a}\right)_{t}-\sigma \bar{\nu}\left(h^{y}\right)_{t} .
$$

The variance of consumption innovations is readily found as:

$$
\begin{array}{r}
V_{c}=(1-\bar{\nu})^{2} V_{a}+\bar{\nu}^{2} V_{d^{y}} \\
+(1-\sigma)^{2}(1-\bar{\nu})^{2} V_{h^{a}} \\
+\sigma^{2} \bar{\nu}^{2} V_{h^{y}}+2(1-\bar{\nu}) \bar{\nu} \operatorname{Corr}_{a, d^{y}} \sqrt{V_{a}} \sqrt{V_{d^{y}}} \\
+2(1-\sigma)(1-\bar{\nu})^{2} \operatorname{Corr}_{a, h^{a}} \sqrt{V_{a}} \sqrt{V_{h^{a}}} \\
-2 \sigma(1-\bar{\nu}) \bar{\nu} \operatorname{Corr}_{a, h^{y}} \sqrt{V_{a}} \sqrt{V_{h^{y}}}+2(1-\sigma)(1-\bar{\nu}) \bar{\nu} \operatorname{Corr}_{h^{a}, d^{y}} \sqrt{V_{d^{y}}} \sqrt{V_{h^{a}}} \\
-2 \sigma \bar{\nu}^{2} \operatorname{Corr}_{h^{y}, d^{y}} \sqrt{V_{d^{y}}} \sqrt{V_{h^{y}}}-2 \sigma(1-\sigma)(1-\bar{\nu}) \bar{\nu} \operatorname{Corr}_{h^{a}, h^{y}} \sqrt{V_{h^{a}}} \sqrt{\left(V_{h^{y}}\right) .}
\end{array}
$$

Similarly, we derive an expression for $V_{c, a}$, the covariance of consumption with asset return innovations:

$$
\begin{array}{r}
V_{c, a}=(1-\bar{\nu}) V_{a}+\bar{\nu} \operatorname{Corr}_{a, d^{y}} \sqrt{V_{a}} \sqrt{V_{d^{y}}} \\
+(1-\sigma)(1-\bar{\nu}) \operatorname{Corr}_{a, h^{a}} \sqrt{V_{a}} \sqrt{V_{h^{a}}}-\sigma \bar{\nu} \operatorname{Corr}_{a, h^{y}} \sqrt{V_{a}} \sqrt{h^{y}}
\end{array}
$$

Note that $\operatorname{Corr}_{a, h^{y}}>0, \operatorname{Corr}_{d^{y}, h^{y}}>0$, and $\operatorname{Corr}_{h^{a}, h^{y}}>0$ keep the variance of consumption innovations and the covariance of consumption innovations with financial asset return innovations low. Likewise, a low variance of news in future human capital returns $\left(V_{h^{y}}\right)$ keeps consumption volatility low.

Log Utility The variance of consumption innovations reduces to:

$$
\begin{array}{r}
V_{c}=(1-\bar{\nu})^{2} V_{a}+\bar{\nu}^{2} V_{d^{y}}+\bar{\nu}^{2} V_{h^{y}}+2(1-\bar{\nu}) \bar{\nu} \\
\left(\operatorname{Corr}_{a, d^{y}} \sqrt{V_{a}} \sqrt{V_{d^{y}}}-\operatorname{Corr}_{a, h^{y}} \sqrt{V_{a}} \sqrt{V_{h^{y}}}\right)-2 \bar{\nu}^{2} \operatorname{Corr}_{h^{y}, d^{y}} \sqrt{V_{d^{y}}} \sqrt{V_{h^{y}}}
\end{array}
$$

while the covariance is given by:

$$
V_{c, a}=(1-\bar{\nu}) V_{a}+\bar{\nu}\left(\operatorname{Corr}_{a, d^{y}} \sqrt{V_{a}} \sqrt{V_{d^{y}}}-\operatorname{Corr}_{a, h^{y}} \sqrt{V_{a}} \sqrt{h^{y}}\right)
$$

More moments Another moment of interest is the correlation between the innovations in human wealth returns $(y)$ and either innovations in financial asset returns $(a)$ or news in future 
financial asset returns $\left(h^{a}\right)$. Now go back to equation (10) and take the covariance with current financial asset return innovations:

$$
V_{a, y}=\operatorname{Corr}_{a, d^{y}} \sqrt{V_{a}} \sqrt{V_{d^{y}}}-\operatorname{Corr}_{a, h^{y}} \sqrt{V_{a}} \sqrt{V_{h^{y}}}
$$

Likewise, take the covariance with news to future stock market returns:

$$
V_{h^{a}, y}=\operatorname{Corr}_{d^{y}, h^{a}} \sqrt{V_{d^{y}}} \sqrt{V_{h^{a}}}-\operatorname{Corr}_{h^{a}, h^{y}} \sqrt{V_{h^{a}}} \sqrt{V_{h^{y}}}
$$

Finally, note that the variance of human capital return innovations is

$$
V_{y}=V_{d^{y}}+V_{h^{y}}-2 V_{d^{y}, h^{y}}
$$

\section{A.2.2 Time-Varying Wealth Share}

Because $d p_{t}^{y}$ is a function of the entire state space, so is $\nu_{t} . \nu_{t+1}$ is not a linear, but a logistic function of the state. We use a linear specification:

$$
\tilde{\nu}_{t} \equiv \nu_{t}-\bar{\nu}=D^{\prime} z_{t}
$$

and we pin down $D(N \times 1)$ using a first order Taylor approximation. Let $s_{t}$ be the labor income share with mean $\bar{s}$ and $w_{t}=d p_{t}^{y}-d p_{t}$ with mean zero. (The mean of $w_{t}$ must be zero to be able to use the same linearization constant $\rho$ for human wealth and financial wealth.) We can linearize the logistic function for the human wealth share $\nu_{t}$ from equation (14) using a first order Taylor approximation around $\left(s_{t}=\bar{s}, w_{t}=0\right)$. We obtain:

$$
\begin{aligned}
\nu_{t}\left(s_{t}, w_{t}\right) & \approx \nu_{t}(\bar{s}, 0)+\left.\frac{\partial \nu_{t}}{\partial s_{t}}\right|_{s_{t}=\bar{s}, w_{t}=0}\left(s_{t}-\bar{s}\right)+\left.\frac{\partial \nu_{t}}{\partial w_{t}}\right|_{s_{t}=\bar{s}, w_{t}=0}\left(w_{t}\right), \\
& \approx \bar{s}+\left(s_{t}-\bar{s}\right)-(\bar{s}(1-\bar{s})) w_{t} \\
& \approx s_{t}-\bar{s}(1-\bar{s}) d p_{t}^{y}+\bar{s}(1-\bar{s}) d p_{t}
\end{aligned}
$$

The average human wealth share is the average labor income share: $\bar{\nu}=\bar{s}$. If $d p_{t}$ is the third element of the VAR, $d p_{t}=e_{3}^{\prime} z_{t}$, and $s_{t}-\bar{s}$ the sixth, and if $d p_{t}^{y}=B^{\prime} z_{t}$, then we can solve for $D$ from equation (33) and $\tilde{\nu}_{t}=D^{\prime} z_{t}$ :

$$
D=e_{6}-\bar{s}(1-\bar{s}) B+\bar{s}(1-\bar{s}) e_{3}
$$

\section{A.2.3 Sylvester Equations}

With the portfolio weights $\nu_{t}$ we can construct consumption innovations according to equation (17). The difficulty is to calculate the terms $W_{1}$ and $W_{2}$. We use value function iteration to pin down $W_{1}$ and $W_{2}$. Let

$$
\begin{aligned}
\widetilde{W}_{1}\left(z_{t+1}\right) & =E_{t+1} \sum_{j=1}^{\infty} \rho^{j} \tilde{\nu}_{t+j} r_{t+1+j}^{a} \\
\widetilde{W}_{1}\left(z_{t+1}\right) & =\tilde{\nu}_{t+1} E_{t+1} \rho r_{t+2}^{a}+E_{t+1} \sum_{j=2}^{\infty} \tilde{\nu}_{t+j} \rho^{j} E_{t+j} r_{t+1+j}^{a} \\
\widetilde{W}_{1}\left(z_{t+1}\right) & =\tilde{\nu}_{t+1}^{\prime} \rho e_{1}^{\prime} A z_{t+1}+\rho E_{t+1} \sum_{j=2}^{\infty} \tilde{\nu}_{t+j} \rho^{j-1} E_{t+j} r_{t+1+j}^{a} \\
& =z_{t+1}^{\prime} D \rho e_{1}^{\prime} A z_{t+1}+\rho E_{t+1} \widetilde{W}_{1}\left(z_{t+2}\right)
\end{aligned}
$$

We can compute a solution to this recursive equation by iterating on it. We posit a quadratic 
objective function:

$$
\widetilde{W}_{1}\left(z_{t+1}\right)=z_{t+1}^{\prime} P z_{t+1}+d
$$

where $P$ solves a matrix Sylvester equation, whose fixed point is found by iterating on:

$$
P_{j+1}=R+\rho A^{\prime} P_{j} A
$$

starting from $P_{0}=0$, and $R=\rho D e_{1}^{\prime} A$. The constant $d$ in the value function equals

$$
d=\frac{\rho}{1-\rho} \operatorname{tr}(P \Sigma)
$$

We are interested in:

$$
\begin{aligned}
W_{1}\left(z_{t+1}\right)=\left(E_{t+1}-E_{t}\right) \widetilde{W}_{1}\left(z_{t+1}\right) & =\left(E_{t+1}-E_{t}\right)\left[z_{t+1}^{\prime} P z_{t+1}+d\right] \\
& =\varepsilon_{t+1}^{\prime} P \varepsilon_{t+1}-E_{t}\left[\varepsilon_{t+1}^{\prime} P \varepsilon_{t+1}\right] \\
& =\varepsilon_{t+1}^{\prime} P \varepsilon_{t+1}-\sum_{i=1}^{N} \sum_{j=1}^{N} \Sigma_{i j} P_{i j}
\end{aligned}
$$

which turns out to be a simple quadratic function of the VAR shocks and the matrix $P$.

In the same manner we calculate $W_{2}$, replacing $R$ in equation (36) by $\rho D C^{\prime}$. $C$ takes on different values for the three canonical models.

\section{A.2.4 Market Return}

We can now compute innovations to the total market return $(m)$ :

$$
\begin{aligned}
(m)_{t+1} & \equiv r_{t+1}^{m}-E_{t}\left[r_{t+1}^{m}\right] \\
& =\left(\tilde{\nu}_{t}+\bar{\nu}\right)\left(r_{t+1}^{y}-E_{t}\left[r_{t+1}^{y}\right]\right)+\left(1-\tilde{\nu}_{t}-\bar{\nu}\right)\left(r_{t+1}^{a}-E_{t}\left[r_{t+1}^{a}\right]\right) \\
& =\left(\tilde{\nu}_{t}+\bar{\nu}\right) I C Y R_{t+1}+\left(1-\tilde{\nu}_{t}-\bar{\nu}\right) I C A R_{t+1} \\
& =\left[\left(\tilde{\nu}_{t}+\bar{\nu}\right)\left(e_{2}^{\prime}-\rho C^{\prime}\right)(I-\rho A)^{-1}+\left(1-\tilde{\nu}_{t}-\bar{\nu}\right) e_{1}^{\prime}\right] \varepsilon_{t+1}
\end{aligned}
$$

and also news in future market returns $\left(h^{m}\right)$ :

$$
\begin{aligned}
\left(h^{m}\right)_{t+1} & \equiv\left(E_{t+1}-E_{t}\right) \sum_{j=1}^{\infty} \rho^{j} r_{t+1+j}^{m} \\
& =\left(E_{t+1}-E_{t}\right) \sum_{j=1}^{\infty} \rho^{j}\left[\left(\tilde{\nu}_{t+j}+\bar{\nu}\right) r_{t+1+j}^{y}+\left(1-\tilde{\nu}_{t+j}-\bar{\nu}\right) r_{t+1+j}^{a}\right] \\
& =\bar{\nu} N F Y R_{t+1}+W_{2, t+1}+(1-\bar{\nu}) N F A R_{t+1}-W_{1, t+1} \\
& =\rho\left[\bar{\nu} C^{\prime}+(1-\bar{\nu}) e_{1}^{\prime} A\right](I-\rho A)^{-1} \varepsilon_{t+1}-\left(\varepsilon_{t+1}^{\prime}(P-Q) \varepsilon_{t+1}\right)-q
\end{aligned}
$$

where the constant $q=\sum_{i=1}^{N} \sum_{j=1}^{N} \Sigma_{i j}\left(P_{i j}-Q_{i j}\right)$.

From the innovations, we back out realized human wealth returns and market returns:

$$
\begin{aligned}
r_{t+1}^{y} & =(y)_{t+1}+C^{\prime} z_{t} \\
r_{t+1}^{m} & =(m)_{t+1}+\left(\tilde{\nu}_{t}+\bar{\nu}\right) C^{\prime} z_{t}+\left(1-\tilde{\nu}_{t}-\bar{\nu}\right) e_{1}^{\prime} A z_{t}
\end{aligned}
$$

\section{A.2.5 Imposing co-integration}

This appendix explains how to impose co-integration between consumption, financial wealth and labor income in our exercise. Much of it follows Campbell (1993) and Lettau and Ludvigson (2001a). We focus on the case of constant wealth shares. 
Deriving the Cointegration Relationship Define total wealth (in levels) to be $M_{t}=$ $A_{t}+H_{t}$; it consists of financial wealth $A$ and human wealth $H$. Denote log variables by lower case letters. Log wealth can be written as $m_{t}=(1-\bar{\nu}) a_{t}+\bar{\nu} h_{t}$, where $\bar{\nu}$ is the human wealth share. Likewise, returns on the market portfolio are a linear combination of returns on financial and human wealth: $r_{t}^{m}=(1-\bar{\nu}) r_{t}^{a}+\bar{\nu} r_{t+1}^{y}$.

We start by linearizing the budget constraint around the mean log consumption-wealth ratio ${ }^{22}$ :

$$
\Delta m_{t+1}=r_{t+1}^{m}+k+\left(1-\frac{1}{\rho}\right)\left(c_{t}-m_{t}\right)
$$

where $k=\log (\rho)-\left(1-\frac{1}{\rho}\right) \overline{c-m}$ and $\rho=1-\exp (\overline{c-m})$. The same equation holds for the growth rate of financial wealth $\Delta a_{t+1}$ :

$$
\Delta a_{t+1}=r_{t+1}^{a}+k+\left(1-\frac{1}{\rho}\right)\left(d_{t}-a_{t}\right)
$$

where $d_{t}$ denotes financial income, and for human wealth changes $\Delta h_{t+1}$ :

$$
\Delta h_{t+1}=r_{t+1}^{y}+k+\left(1-\frac{1}{\rho}\right)\left(y_{t}-h_{t}\right)
$$

We have assumed that the linearization constants $k$ and $\rho$ are the same for the three sources of wealth. ${ }^{23}$

The next step is to iterate forward each of these three equations. For example, we substitute the identity $\Delta m_{t+1}=\Delta c_{t+1}+\left(c_{t}-m_{t}\right)-\left(c_{t+1}-m_{t+1}\right)$ into equation (37) and impose $\lim _{j \rightarrow \infty} \rho^{j}\left(c_{t+j}-\right.$ $\left.m_{t+j}\right)=0$ to get an expression for the consumption-wealth ratio, the dividend price ratio on total wealth:

$$
c_{t}-m_{t}=\sum_{j=1}^{\infty} \rho^{j}\left(r_{t+j}^{m}-\Delta c_{t+j}\right)+\frac{\rho k}{1-\rho} .
$$

Likewise, we obtain the dividend-price ratio on financial wealth:

$$
d_{t}-a_{t}=\sum_{j=1}^{\infty} \rho^{j}\left(r_{t+j}^{a}-\Delta d_{t+j}\right)+\frac{\rho k}{1-\rho}
$$

and on human wealth:

$$
y_{t}-h_{t}=\sum_{j=1}^{\infty} \rho^{j}\left(r_{t+j}^{y}-\Delta y_{t+j}\right)+\frac{\rho k}{1-\rho} .
$$

The last step is to substitute the expressions for $m$ and $r^{m}$ into the expression for $c_{t}-m_{t}$

$$
c_{t}-(1-\bar{\nu}) a_{t}-\bar{\nu} h_{t}=\sum_{j=1}^{\infty} \rho^{j}\left((1-\bar{\nu}) r_{t+j}^{a}+\bar{\nu} r_{t+j}^{y}-\Delta c_{t+j}\right)+\frac{\rho k}{1-\rho},
$$

to solve (40) for $h_{t}$ and to substitute this expression into the above equation:

$$
c_{t}-(1-\bar{\nu}) a_{t}-\bar{\nu} y_{t}=\sum_{j=1}^{\infty} \rho^{j}\left((1-\bar{\nu}) r_{t+j}^{a}+\bar{\nu} \Delta y_{t+j}-\Delta c_{t+j}\right)+(1-\bar{\nu}) \frac{\rho k}{1-\rho} .
$$

This expression hold ex-post but also ex-ante. Imposing that $E_{t} \sum_{j=1}^{\infty} \rho^{j}\left((1-\bar{\nu}) r_{t+j}^{a}+\bar{\nu} \Delta y_{t+j}-\right.$

\footnotetext{
${ }^{22}$ This is an approximation which we take to be the true model.

${ }^{23}$ It follows from the expressions for $\Delta m_{t+1}, \Delta a_{t+1}$, and $\Delta h_{t+1}$, and from $\Delta m_{t+1}=(1-\bar{\nu}) \Delta a_{t+1}+\bar{\nu} \Delta h_{t+1}$ that $c_{t}-m_{t}=(1-\bar{\nu})\left(d_{t}-a_{t}\right)+\bar{\nu}\left(y_{t}-h_{t}\right)$, i.e. the log dividend price ratios on the wealth components are linearly related.
} 
$\left.\Delta c_{t+j}\right)$ is stationary, the left-hand side must also be stationary. This is the co-integration relationship between consumption, financial wealth and labor income, or cay, from Lettau and Ludvigson (2001a).

Empirical Proxy for Consumption-Wealth Ratio Lettau and Ludvigson (2001a) argue that non-durable consumption and services is only a fraction of total consumption and postulate $\lambda c_{t}=c_{t}^{\text {total }}$. They then estimate the co-integration coefficients by dynamic least squares:

$$
c_{t}=\alpha+\beta_{a} a_{t}+\beta_{y} y_{t}+\sum_{j=-k}^{k} b_{a, j} \Delta a_{t+j}+\sum_{j=-k}^{k} b_{y, j} \Delta y_{t+j} .
$$

where $\alpha=\frac{1-\bar{\nu}}{\lambda} \frac{\rho k}{1-\rho}, \beta_{a}=\frac{1-\bar{\nu}}{\lambda}$, and $\beta_{y}=\frac{\bar{\nu}}{\lambda}$. In our data, we find little support for $\lambda>1(\lambda=1.017)$, and set it equal to 1 for simplicity. We use the model-implied co-integration weights $(1-\bar{\nu}, \bar{\nu})$ instead of estimating them. In the model with constant wealth shares, $\bar{\nu}=\bar{s}$, the labor income share which is 0.73172 in our data. So, our measure of cay is:

$$
\operatorname{cay}_{t}=c_{t}-0.26728 a_{t}-0.73172 y_{t}
$$

The state vector $z$ contains the same elements as before, except that the first element, the return on financial assets $r^{a}$, must be replaced by real per capita financial wealth growth $\Delta a_{t+1}$. We construct this measure from equation (38) using data on the financial return $r_{t+1}^{a}$ and the lagged dividend-price ratio $d_{t}-a_{t}$. The linearization constants are found using the sample mean of $\overline{d-a}$ to form $k=\log (\rho)-\left(1-\frac{1}{\rho}\right) \overline{d-a}$ and $\rho=1-\exp (\overline{d-a})$. In other words, we construct $\Delta a_{t+1}$ so that equation (38) holds exactly, not approximately.

We then estimate the VECM (equation 22 in the main text) and form the cay-augmented VAR (equation 23 in the main text). We then redefine the companion matrix $A$ to be the $8 \times 8$ companion matrix of the augmented VAR system and $\varepsilon$ to be the augmented $8 \times T$ innovation vector. We note that its covariance matrix is singular, because the $8^{\text {th }}$ element is a linear combination of three elements of the original $7 \times 1$ innovation vector.

The last step is to extract the news components that drive the consumption growth innovations. We only write out the expressions that have changed:

$$
\begin{aligned}
(a)_{t+1} & =r_{t+1}^{a}-E_{t}\left[r_{t+1}^{a}\right]=\Delta a_{t+1}-E_{t}\left[\Delta a_{t+1}\right]=e_{1}^{\prime} \varepsilon_{t+1} \\
\left(f^{d}\right)_{t+1} & =\Delta d_{t+1}-E_{t}\left[\Delta d_{t+1}\right]=\left(e_{1}^{\prime}+e_{3}^{\prime}\right) \varepsilon_{t+1} \\
\left(h^{a}\right)_{t+1} & =\left(E_{t+1}-E_{t}\right) \sum_{j=1}^{\infty} \rho^{j} r_{t+1+j}^{a} \\
& =\left(E_{t+1}-E_{t}\right) \sum_{j=1}^{\infty} \rho^{j} \Delta a_{t+1+j}-\left(1-\frac{1}{\rho}\right)\left(E_{t+1}-E_{t}\right) \sum_{j=1}^{\infty} \rho^{j}\left(d_{t+j}-a_{t+j}\right) \\
& =\left[e_{1}^{\prime} \rho A+e_{3}^{\prime}(1-\rho)\right](I-\rho A)^{-1} \varepsilon_{t+1},
\end{aligned}
$$

with the understanding that news about current and future dividend growth is formed as before:

$$
\left(d^{a}\right)_{t+1}=\left(h^{a}\right)_{t+1}+(a)_{t+1}
$$

The last change is that the conditional expectation of demeaned financial returns is a function of the conditional expectation of demeaned financial wealth growth and the lagged dividend-price ratio:

$$
E_{t}\left[r_{t+1}^{a}\right]=E_{t}\left[\Delta a_{t+1}\right]-\left(1-\frac{1}{\rho}\right)\left(d_{t}-a_{t}\right)=\frac{1}{\rho}\left[e_{1}^{\prime} \rho A+e_{3}^{\prime}(1-\rho)\right] z_{t} .
$$

The rest of the analysis proceeds as before, but with the augmented VAR. 


\section{A.2.6 Long-Run Restriction}

The household budget constraint imposes a restriction on the long-run effect of news about market returns and consumption growth:

$$
\left(E_{t+1}-E_{t}\right) \sum_{j=0}^{\infty} \rho^{j} r_{t+1+j}^{m}=\left(E_{t+1}-E_{t}\right) \sum_{j=0}^{\infty} \rho^{j} \Delta c_{t+1+j} .
$$

In our notation: $(m)_{t}+\left(h^{m}\right)_{t}=\left(d^{c}\right)_{t}$.

Long-Run Restriction on Consumption Growth in Data As pointed out in Hansen, Roberds, and Sargent (1991) this restriction cannot be satisfied for the models with constant wealth shares. To see why, we can rewrite it s $^{24}$

$$
(1-\bar{\nu})\left(d^{a}\right)_{t}+\bar{\nu}\left(d^{y}\right)_{t}=\left(d^{c}\right)_{t}
$$

Since consumption growth is taken from the data (it is the seventh element in the VAR), the long-run response of consumption growth can be computed as:

$$
\left(d^{c}\right)_{t+1}=\left(E_{t+1}-E_{t}\right) \sum_{j=0}^{\infty} \rho^{j} \Delta c_{t+1+j}=e_{7}^{\prime}(I-\rho A)^{-1} \varepsilon_{t+1} .
$$

Likewise,

$$
\left(d^{y}\right)_{t+1}=\left(E_{t+1}-E_{t}\right) \sum_{j=0}^{\infty} \rho^{j} \Delta y_{t+1+j}=e_{2}^{\prime}(I-\rho A)^{-1} \varepsilon_{t+1} .
$$

Finally, news about current and future financial income growth is

$$
\left(d^{a}\right)_{t+1}=(a)_{t+1}+\left(h^{a}\right)_{t+1}=\left[e_{1}^{\prime}+e_{1}^{\prime} \rho A(I-\rho A)^{-1}\right] \varepsilon_{t+1} .
$$

The equality between news about long run returns and consumption growth should hold for all $\varepsilon_{t+1}$. Thus, the constraint imposes that

$$
(1-\bar{\nu})\left[e_{1}^{\prime}+e_{1}^{\prime} \rho A(I-\rho A)^{-1}\right]+\bar{\nu} e_{2}^{\prime}(I-\rho A)^{-1}=e_{7}^{\prime}(I-\rho A)^{-1},
$$

or post-multiplying by $(I-\rho A)$ shows this implies:

$$
(1-\bar{\nu}) e_{1}^{\prime}+\bar{\nu} e_{2}^{\prime}=e_{7}^{\prime}
$$

which cannot be satisfied because the vector on the right hand side has zeros in all entries but the seventh, while the left-hand side has non-zero elements in the first and second entries. So, the linearity of the VAR implies that the budget constraint cannot be satisfied exactly for all innovations.

Long-Run Restriction on Consumption Growth in Model The same restriction is also violated for model-implied consumption innovations. Recall the optimal consumption rule

\footnotetext{
${ }^{24}$ In the constant wealth share case, we obtain:

$$
\begin{aligned}
(m)_{t}+\left(h^{m}\right)_{t} & =(1-\bar{\nu})(a)_{t+1}+(1-\bar{\nu})\left(h^{a}\right)_{t+1}+\bar{\nu}(y)_{t+1}+\bar{\nu}\left(h^{y}\right)_{t+1} \\
& =(1-\bar{\nu})\left[(a)_{t+1}+\left(h^{a}\right)_{t+1}\right]+\bar{\nu}\left(d^{y}\right)_{t+1} \\
& =(1-\bar{\nu})\left(d^{a}\right)_{t+1}+\bar{\nu}\left(d^{y}\right)_{t+1}
\end{aligned}
$$
}

where we have used that $(y)_{t+1}=\left(d^{y}\right)_{t+1}-\left(h^{y}\right)_{t+1}$ and $\left(d^{a}\right)_{t+1}=(a)_{t+1}+\left(h^{a}\right)_{t+1}$. 
which follows from the Euler equation:

$$
\begin{aligned}
(c)_{t+1} & =(1-\bar{\nu})(a)_{t+1}+\bar{\nu}\left(d^{y}\right)_{t+1}-\sigma \bar{\nu}\left(h^{y}\right)_{t+1}+(1-\sigma)(1-\bar{\nu})\left(h^{a}\right)_{t+1}, \\
& =\left[(1-\bar{\nu}) e_{1}^{\prime}+\bar{\nu} e_{2}^{\prime}(I-\rho A)^{-1}-\sigma \bar{\nu} C^{\prime} \rho(I-\rho A)^{-1}+(1-\sigma)(1-\bar{\nu}) e_{1}^{\prime} \rho A(I-\rho A)^{-1}\right] \varepsilon_{t+1}
\end{aligned}
$$

where we have used $h^{y}=C^{\prime} \rho(I-\rho A)^{-1} \varepsilon_{t+1}$. For the discounted infinite sum of consumption innovations, we get $\left(d^{c}\right)_{t+1}=(I-\rho A)^{-1}(c)_{t+1}$. This needs to equal

$$
(m)_{t}+\left(h^{m}\right)_{t}=\left[(1-\bar{\nu})\left[e_{1}^{\prime}+e_{1}^{\prime} \rho A(I-\rho A)^{-1}\right]+\bar{\nu} e_{2}^{\prime}(I-\rho A)^{-1}\right] \varepsilon_{t+1} .
$$

This implies that the following equality must hold for all $\varepsilon_{t+1}$ :

$$
(1-\bar{\nu}) e_{1}^{\prime}+\bar{\nu} e_{2}^{\prime}(I-\rho A)^{-1}-\sigma \bar{\nu} C^{\prime} \rho(I-\rho A)^{-1}+(1-\sigma)(1-\bar{\nu}) e_{1}^{\prime} \rho A(I-\rho A)^{-1}=(1-\bar{\nu}) e_{1}^{\prime}+\bar{\nu} e_{2}^{\prime}
$$

which would require singularity of $A$. To conclude, in the models with constant wealth shares, we cannot test the long-run restriction.

Long-Run restriction in Model with Time-Varying Wealth Shares Importantly, for the models with time-varying wealth shares $\nu_{t}$, the above argument does not go through. Recall the definition of the human wealth share in terms of its mean and its deviations from the mean: $\nu_{t}=\bar{\nu}+\tilde{\nu}_{t}$. We obtain:

$$
\begin{aligned}
(m)_{t}+\left(h^{m}\right)_{t}= & \left(1-\bar{\nu}-\tilde{\nu}_{t}\right)(a)_{t+1}+\left(E_{t+1}-E_{t}\right) \sum_{j=1}^{\infty} \rho^{j}\left(1-\bar{\nu}-\tilde{\nu}_{t+j}\right) r_{t+1+j}^{a} \\
& +\left(\bar{\nu}+\tilde{\nu}_{t}\right)(y)_{t+1}+\left(E_{t+1}-E_{t}\right) \sum_{j=1}^{\infty} \rho^{j}\left(\bar{\nu}+\tilde{\nu}_{t+j}\right) r_{t+1+j}^{y}
\end{aligned}
$$

Using the definitions for news about weighted future financial asset returns $\left(W_{t+1}^{1}\right)$ and human wealth returns $\left(W_{t+1}^{2}\right)$ from appendices A.2.2 and (A.2.3), the expression for model-implied cashflow news in consumption reduces to:

$$
\begin{aligned}
(m)_{t}+\left(h^{m}\right)_{t}= & \left(1-\bar{\nu}-\tilde{\nu}_{t}\right)(a)_{t+1}+\left(\tilde{\nu}_{t}+\bar{\nu}\right)\left(d^{y}\right)_{t+1}-\tilde{\nu}_{t}\left(h^{y}\right)_{t+1} \\
& +(1-\bar{\nu})\left(h^{a}\right)_{t+1}-\left(W_{t+1}^{1}-W_{t+1}^{2}\right)
\end{aligned}
$$

Now, $W^{1}$ and $W^{2}$ are quadratic, not linear. The problem that arose before, is gone because of the nonlinearity. The condition that this expression equals the long-run consumption growth response $\left(d^{c}\right)$ does not simplify as before, because of the quadratic terms. In addition, modelimplied consumption is nonlinear as well (see equation 17). 
Figure 1: Dividend Yield on CRSP Value-Weighted Stock Market Index and Payout-Yield on Total Firm Value

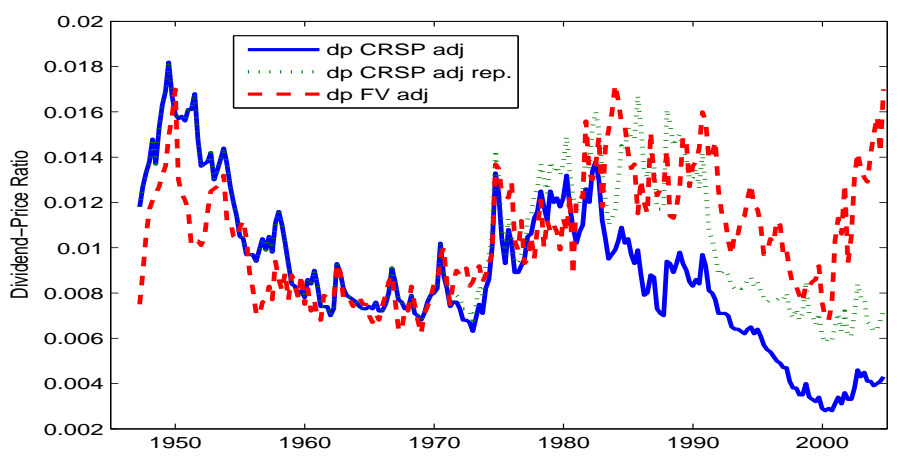

Figure 2: Matching Moments of Consumption Innovations

The first panel plots the quarterly model-implied standard deviation of consumption innovations against the EIS $\sigma$, while the second panel plots the model-implied correlation of consumption innovations. We use the returns on total firm value. The sample is 1947-II-2004.III.
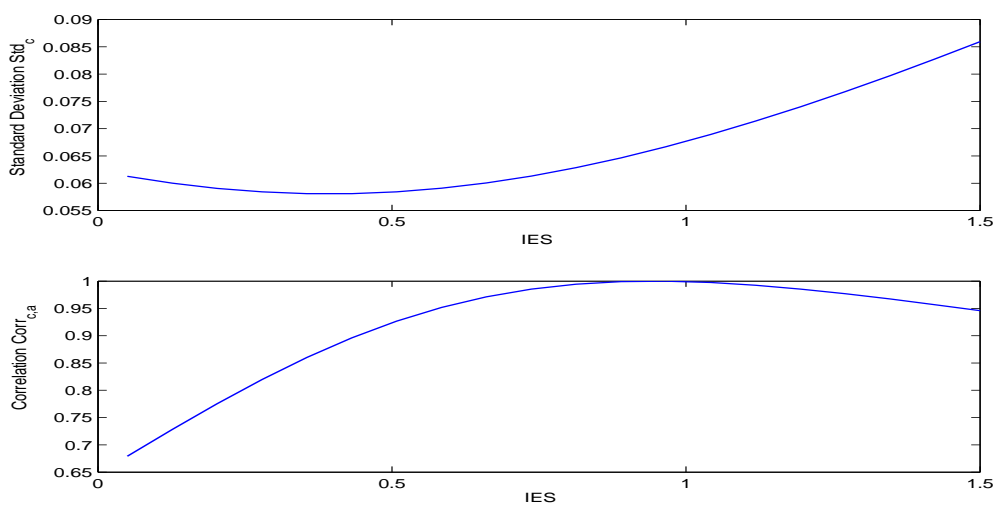
Figure 3: The EIS and Consumption Innovation Variance and Correlation: 3 Benchmark Models

Using Returns on Firm Value, Quarterly Data 1947-2003. The labor share $\bar{s}=\bar{\nu}$ is .70.
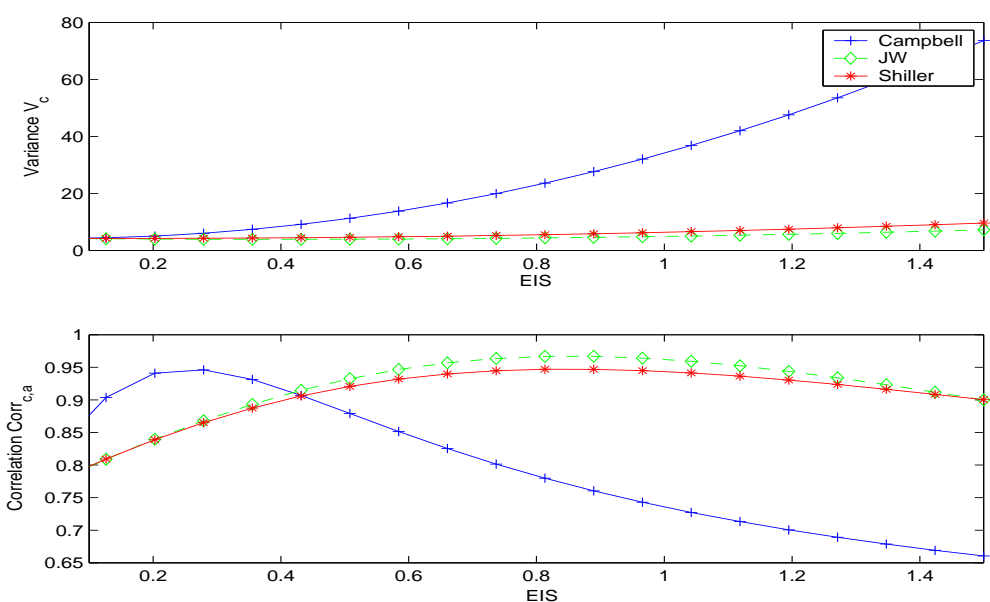

Figure 4: The Labor Share and Consumption Innovation Variance and Correlation: 3 Benchmark Models

Using Returns on Firm Value, Quarterly Data 1947-2003. The EIS $\sigma$ is .28.
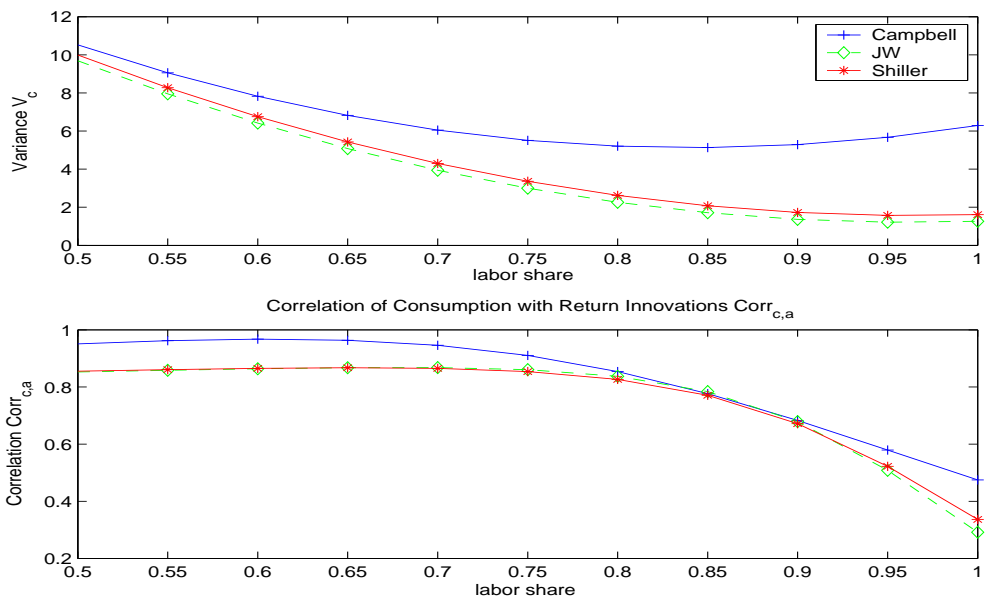
Figure 5: Labor Income Share and Human Wealth Share for Models 2, 3, and 4 The return on financial assets is return on Firm Value.

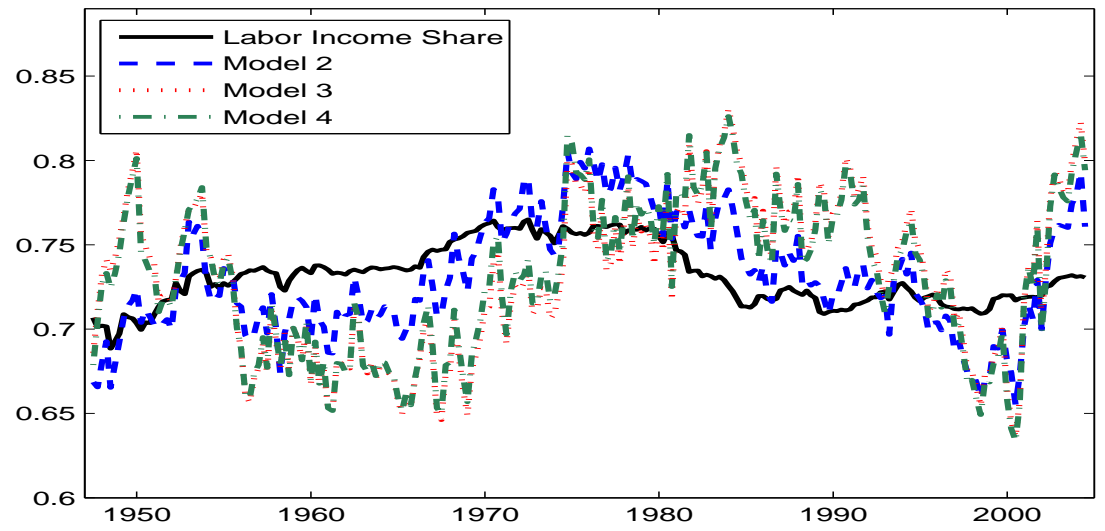

Figure 6: Human Wealth Share in Model 5.

The return on financial assets is the return on firm value.

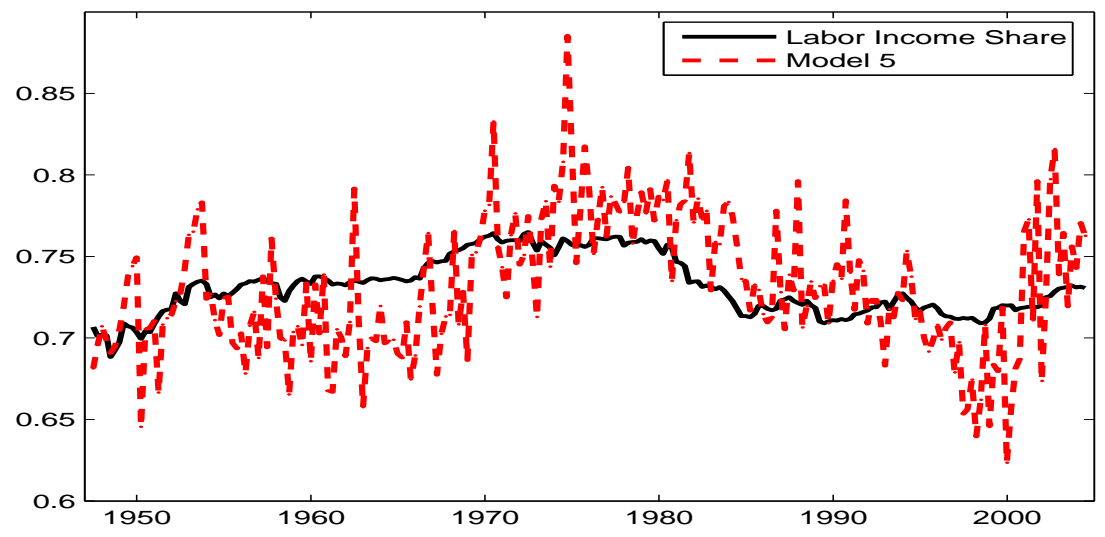


Figure 7: Value Portfolios: Risk Contributions of $c$ and $m$
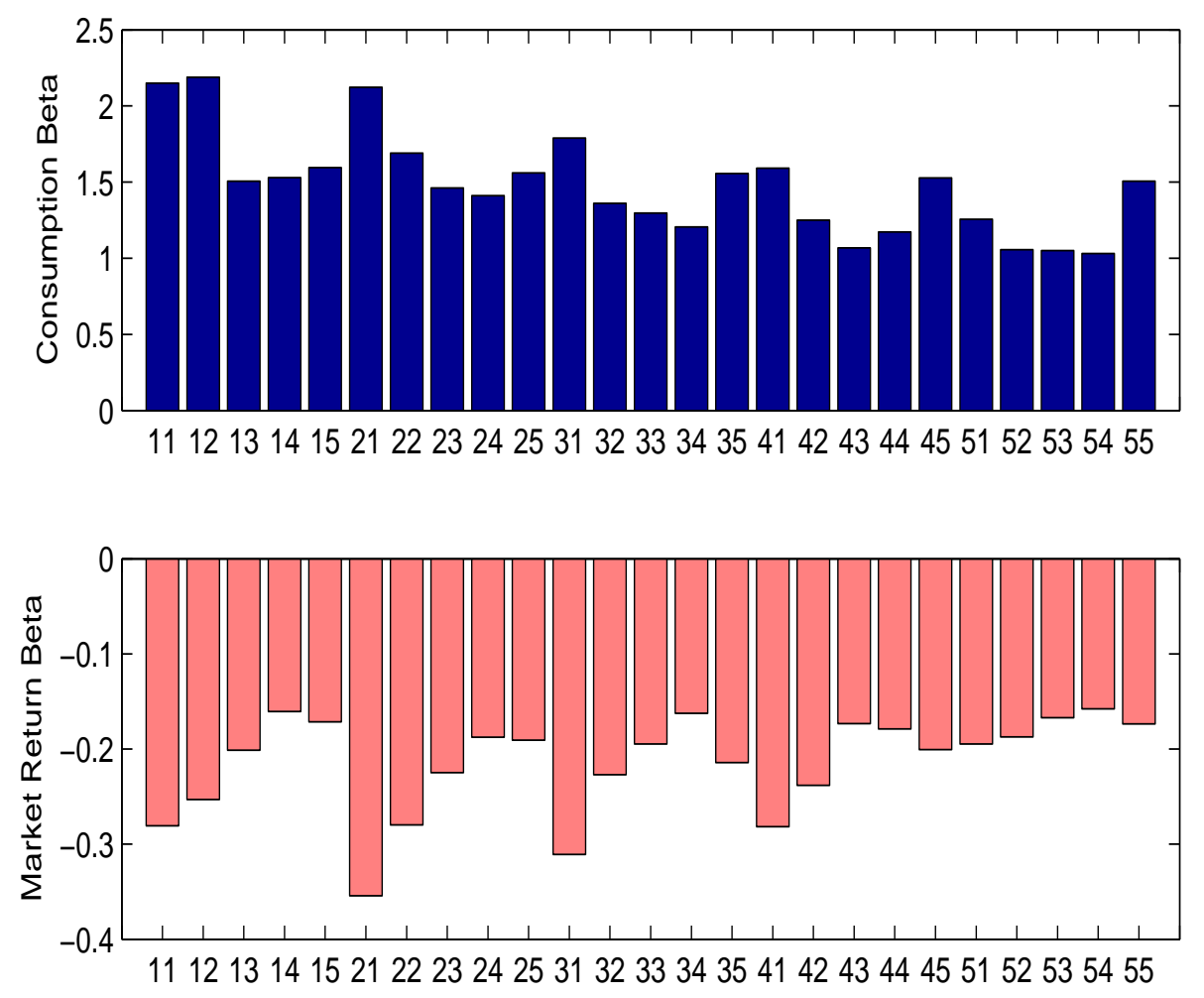
Table 1: Moments from Data: Returns on Firm Value

The table reports variances $(V)$ and correlations Corr in the data. The sample covers 1947.II-2004.III. In the left panel, the asset return is the return on firm value (own computation). In the right panel, it is the return on the value-weighted CRSP stock index. The first column reports results for a 1-lag VAR with quarterly data. The second column reports results for a 2-lag VAR with quarterly data. The third column reports the results for annual data over the same period 1947-2004. The subscript $a$ denotes innovations in current financial asset returns; $d^{y}$ denotes news in current and future labor income growth; $h^{a}$ denotes news in future financial market returns,; $d^{a}$ denotes news in current and future financial dividend growth; and $c$ denotes innovations to non-durable and services consumption.

\begin{tabular}{l|ccc|ccc}
\hline & \multicolumn{3}{|c|}{ Firm Value Returns } & \multicolumn{3}{c}{ Stock Return Returns } \\
\hline Moments & 1 Lag & 2 Lags & Annual & 1 Lag & 2 Lags & Annual \\
\hline$V_{a}$ & 48.31 & 47.74 & 185.12 & 63.54 & 62.74 & 242.96 \\
$V_{d^{y}}$ & 1.61 & 1.90 & 6.67 & 1.65 & 1.92 & 6.95 \\
$V_{h^{a}}$ & 32.67 & 32.97 & 47.44 & 103.07 & 98.37 & 231.85 \\
Corr $_{a, h^{a}}$ & -.477 & -.625 & -0.487 & -.918 & -.805 & -0.760 \\
$\operatorname{Corr}_{a, d^{y}}$ & .337 & .377 & 0.599 & .491 & .473 & 0.329 \\
$\operatorname{Corr}_{d^{y}, h^{a}}$ & -.525 & -.656 & -0.818 & -.336 & -.208 & -0.196 \\
\cline { 2 - 7 }$V_{c}$ & .333 & .325 & 0.681 & .328 & .321 & 0.642 \\
$\operatorname{Corr}_{c, a}$ & .168 & .168 & 0.163 & .185 & .175 & 0.208 \\
\cline { 2 - 7 } $\operatorname{Corr}_{d^{y}, d^{a}}$ & -.101 & -.209 & 0.166 & .118 & .286 & 0.200 \\
$\operatorname{Corr}_{f^{y}, f^{d}}$ & -.092 & -.081 & -0.259 & .173 & .114 & 0.139 \\
\hline
\end{tabular}

Table 2: Moments for Consumption Growth and Human Capital Returns - Constant Wealth Shares.

The left panel uses firm value returns, the right panel uses stock returns. All results are for the full sample 1947.II2004.III. In each panel, the first column is Model 2, with human capital returns implied by $C^{\prime}=e_{1}^{\prime} A$. The second column represents the constant discounter Model $2\left(C^{\prime}=0\right)$, and the third column represents Model $4\left(C^{\prime}=e_{2}^{\prime} A\right)$. The last column gives the moments of human wealth returns that are consistent with consumption data (equations 6 and 20). Computations are done for $\bar{\nu}=.70$ and $\sigma=.28$. In the data, $V_{c}=.33$ and $\operatorname{Corr}_{c, a}=0.168$ in panel A and $V_{c}=.33$ and $\operatorname{Corr}_{c, a}=0.185$ in panel B.

\begin{tabular}{|c|c|c|c|c|c|c|c|c|}
\hline Moments & Model 2 & Model 3 & Model 4 & Reverse & Model 2 & Model 3 & Model 4 & Reverse \\
\hline & \multicolumn{4}{|c|}{ Panel A: Firm Value Returns } & \multicolumn{4}{|c|}{ Panel B: Stock Returns } \\
\hline$V_{h y}$ & 32.67 & 0 & .54 & 107.38 & 103.07 & 0 & .79 & 58.37 \\
\hline $\operatorname{Corr}_{a, h^{y}}$ & -.477 & 0 & .485 & .839 & -.918 & 0 & .644 & .476 \\
\hline $\operatorname{Corr}_{d^{y}, h^{y}}$ & -.525 & 0 & .752 & .324 & -.336 & 0 & .735 & .704 \\
\hline $\operatorname{Corr}_{h^{a}, h^{y}}$ & 1.000 & 0 & -.306 & -.037 & 1.000 & 0 & -.453 & -.137 \\
\hline$V_{y}$ & 41.91 & 1.61 & .75 & 100.46 & 113.48 & 1.65 & .76 & 46.22 \\
\hline $\operatorname{Corr}_{y, a}$ & .487 & .337 & .081 & -.825 & .934 & .491 & .065 & -.443 \\
\hline $\operatorname{Corr}_{y, h^{a}}$ & -.986 & -.525 & -.511 & -.029 & -.994 & -.336 & -.032 & .091 \\
\hline$V_{c}$ & 6.05 & 4.30 & 3.95 & 0.33 & 7.61 & 2.49 & 2.10 & .33 \\
\hline $\operatorname{Corr}_{c, a}$ & .946 & .865 & .868 & .168 & .955 & .518 & .486 & .185 \\
\hline$V_{m}$ & 34.52 & 5.51 & 4.07 & 29.45 & 96.47 & 7.43 & 5.16 & 18.29 \\
\hline $\operatorname{Corr}_{m, a}$ & .710 & .928 & .950 & -.682 & .959 & .954 & .960 & .066 \\
\hline $\operatorname{Corr}_{m, y}$ & .961 & .664 & .389 & .976 & .997 & .730 & .342 & .865 \\
\hline $\operatorname{Corr}_{m, h^{m}}$ & -.946 & -.587 & -.436 & -.994 & -.988 & -.836 & -.790 & -.991 \\
\hline
\end{tabular}


Table 3: Matching Consumption Moments when $\sigma<1$

In the first panel, the entries show the sign of the effect of the variance/covariance of $(i, j)$ on the variance of consumption $V_{c}$. In the second panel, the entries show the sign of the effect of the variance/covariance of $(i, j)$ on the covariance of consumption $V_{c, a}$.

\begin{tabular}{|c|c|c|c|c|}
\hline & $a$ & $d^{y}$ & $h^{a}$ & $h^{2}$ \\
\hline & \multicolumn{4}{|c|}{$V_{c}$} \\
\hline$a$ & + & + & + & - \\
\hline$d^{y}$ & & + & + & - \\
\hline$h^{a}$ & & & + & - \\
\hline \multirow[t]{2}{*}{$h^{y}$} & \multirow{2}{*}{\multicolumn{4}{|c|}{$V_{c, a}$}} \\
\hline & & & & \\
\hline$a$ & + & + & + & - \\
\hline
\end{tabular}

Table 4: Moments for Consumption Growth and Human Capital Returns - Time-Varying Wealth Shares

This table has the same structure as Table 2,but here computations are done for a time-varying human wealth share $\nu_{t}$ and $\sigma=.28$.

\begin{tabular}{|c|c|c|c|c|c|c|c|c|}
\hline Moments & Model 2 & Model 3 & Model 4 & Model 5 & Model 2 & Model 3 & Model 4 & Model 5 \\
\hline & \multicolumn{4}{|c|}{ Panel A: Firm Value Returns } & \multicolumn{4}{|c|}{ Panel B: Stock Returns } \\
\hline$V_{h y}$ & 32.67 & 0 & .54 & 69.05 & 103.07 & 0 & .79 & 36.38 \\
\hline $\operatorname{Corr}_{a, h^{y}}$ & -.477 & 0 & .485 & .897 & -.918 & 0 & .644 & .504 \\
\hline $\operatorname{Corr}_{d^{y}, h^{y}}$ & -.525 & 0 & .752 & .452 & -.336 & 0 & .735 & .874 \\
\hline $\operatorname{Corr}_{h^{a}, h^{y}}$ & 1.000 & 0 & -.306 & -.152 & 1.000 & 0 & -.453 & -.209 \\
\hline$V_{y}$ & 41.91 & 1.61 & .75 & 61.13 & 113.48 & 1.65 & .76 & 24.50 \\
\hline $\operatorname{Corr}_{y, a}$ & .487 & .337 & .081 & -.880 & .934 & .491 & .065 & -.487 \\
\hline $\operatorname{Corr}_{y, h^{a}}$ & -.986 & -.525 & -.511 & .076 & -.994 & -.336 & -.032 & .168 \\
\hline$V_{c}$ & 5.65 & 3.84 & 3.46 & .52 & 8.00 & 2.77 & 2.41 & .47 \\
\hline $\operatorname{Corr}_{c, a}$ & .922 & .848 & .853 & .168 & .955 & .511 & .473 & .185 \\
\hline$V_{m}$ & 34.62 & 5.69 & 4.21 & 18.92 & 96.09 & 7.75 & 5.46 & 10.10 \\
\hline $\operatorname{Corr}_{m, a}$ & .707 & .917 & .937 & -.759 & .961 & .939 & .937 & .067 \\
\hline $\operatorname{Corr}_{m, y}$ & .961 & .667 & .392 & .971 & .996 & .736 & .353 & .825 \\
\hline $\operatorname{Corr}_{m, h^{m}}$ & -.948 & -.584 & -.430 & -.987 & -.987 & -.810 & -.748 & -.980 \\
\hline
\end{tabular}


Table 5: Moments for Consumption Growth and Human Capital Returns - Model 5 Sensitivity to EIS.

The table reports the same moments as Table 2. All results are for Model 5 with time-varying human wealth share. The first column is for $\sigma=.5$, the second column is for $\sigma=1$, and the last column is for $\sigma=1.5$. The sample is 1947.II-2004.III. Financial asset returns are firm value returns in panel A and stock returns in panel B.

\begin{tabular}{|c|c|c|c|c|c|c|}
\hline Moments & $\sigma=.5$ & $\sigma=1$ & $\sigma=1.5$ & $\sigma=.5$ & $\sigma=1$ & $\sigma=1.5$ \\
\hline & Panel & :Firm & Value Returns & \multicolumn{3}{|c|}{ Panel B: Stock Returns } \\
\hline$V_{h y}$ & 24.36 & 8.59 & 5.91 & 18.10 & 12.58 & 11.81 \\
\hline $\operatorname{Corr}_{a, h y}$ & .941 & .967 & .914 & .791 & .956 & .978 \\
\hline $\operatorname{Corr}_{d^{y}, h^{y}}$ & .466 & .561 & .604 & .751 & .704 & .643 \\
\hline $\operatorname{Corr}_{h^{a} \cdot h^{y}}$ & -.280 & -.588 & -.757 & -.512 & -.809 & -.905 \\
\hline$V_{y}$ & 20.14 & 6.02 & 3.79 & 11.55 & 7.82 & 7.79 \\
\hline $\operatorname{Corr}_{y, a}$ & -.940 & -.980 & -.922 & -.805 & -.987 & -.978 \\
\hline $\operatorname{Corr}_{y, h^{a}}$ & .159 & .430 & .603 & .515 & .872 & .960 \\
\hline$V_{c}$ & .33 & .33 & .33 & .33 & .33 & .41 \\
\hline $\operatorname{Corr}_{c, a}$ & .168 & .168 & .168 & .185 & .185 & .185 \\
\hline$V_{m}$ & 3.12 & .33 & .82 & 2.21 & .33 & .66 \\
\hline $\operatorname{Corr}_{m, a}$ & -.719 & .168 & .614 & .032 & .185 & .188 \\
\hline $\operatorname{Corr}_{m, y}$ & .895 & -.036 & -.318 & .546 & -.116 & -.056 \\
\hline $\operatorname{Corr}_{m, h^{m}}$ & -.947 & .199 & .779 & -.925 & -.052 & .625 \\
\hline
\end{tabular}

Table 6: Moments for Consumption Growth and Human Capital Returns - Imposing Cointegration.

The left panel uses firm value returns, the right panel uses stock returns. All results are for the full sample 1947.II2004.III. In each panel, the first column is Model 2, with human capital returns implied by $C^{\prime}=e_{1}^{\prime} A$. The second column represents the constant discounter Model $2\left(C^{\prime}=0\right)$, and the third column represents Model $4\left(C^{\prime}=e_{2}^{\prime} A\right)$. The last column gives the moments of human wealth returns that are consistent with consumption data (equations 6 and 20). Computations are done for $\bar{\nu}=0.7317$ and $\sigma=.28$. In the data, $V_{c}=.31$ and $\operatorname{Corr}_{c, a}=0.196$ in panel $\mathrm{A}$ and $V_{c}=.31$ and $\operatorname{Corr}_{c, a}=0.183$ in panel B.

\begin{tabular}{|c|c|c|c|c|c|c|c|c|}
\hline Moments & Model 2 & Model 3 & Model 4 & Reverse & Model 2 & Model 3 & Model 4 & Reverse \\
\hline & \multicolumn{4}{|c|}{ Panel A: Firm Value Returns } & \multicolumn{4}{|c|}{ Panel B: Stock Returns } \\
\hline$V_{h y}$ & 11.56 & 0 & .54 & 106.71 & 11.28 & 0 & .81 & 95.81 \\
\hline $\operatorname{Corr}_{a, h^{y}}$ & -.566 & 0 & .503 & .921 & -.911 & 0 & -.007 & .870 \\
\hline $\operatorname{Corr}_{d^{y}, h^{y}}$ & -.580 & 0 & .756 & .440 & -.002 & 0 & .733 & .378 \\
\hline $\operatorname{Corr}_{h^{a}, h y}$ & 1.000 & 0 & -.436 & -.376 & 1.000 & 0 & .008 & -.674 \\
\hline$V_{y}$ & 18.17 & 1.61 & .74 & 96.78 & 12.92 & 1.63 & .75 & 88.00 \\
\hline Corr $_{y, a}$ & .553 & .340 & .074 & -.923 & .865 & .037 & .063 & -.903 \\
\hline $\operatorname{Corr}_{y, h^{a}}$ & -.970 & -.579 & -.482 & .320 & -.935 & -.002 & -.011 & .703 \\
\hline$V_{c}$ & 6.14 & 4.43 & 4.05 & .31 & 6.39 & 4.04 & 3.85 & .31 \\
\hline $\operatorname{Corr}_{c, a}$ & .945 & .935 & .942 & .196 & .935 & .878 & .901 & .183 \\
\hline$V_{m}$ & 19.59 & 5.49 & 4.02 & 25.34 & 21.21 & 5.59 & 5.14 & 20.48 \\
\hline $\operatorname{Corr}_{m, a}$ & .809 & .928 & .950 & -.849 & .958 & .919 & .960 & -.783 \\
\hline $\operatorname{Corr}_{m, y}$ & .937 & .666 & .382 & .987 & .972 & .428 & .339 & .974 \\
\hline $\operatorname{Corr}_{m, h^{m}}$ & -.921 & -.678 & -.385 & -.994 & -.957 & -.825 & -.689 & -.992 \\
\hline
\end{tabular}


Table 7: Moments for Consumption Growth and Human Capital Returns - Constant Wealth Shares - Using Labor Income Growth Implied by the Long-Run Restriction.

Same as Table 2, except that $\left(d^{y}\right)$ is computed from equation (25) using consumption and financial income data instead of labor income data. Computations are done for $\bar{\nu}=.70$ and $\sigma=.28$. In the data, $V_{c}=.33$ and $\operatorname{Corr}_{c, a}=0.168$ in panel $\mathrm{A}$ and $V_{c}=.33$ and $\operatorname{Corr}_{c, a}=0.185$ in panel B.

\begin{tabular}{|c|c|c|c|c|c|c|c|c|}
\hline Moments & Model 2 & Model 3 & Model 4 & Reverse & Model 2 & Model 3 & Model 4 & Reverse \\
\hline & \multicolumn{4}{|c|}{ Panel A: Firm Value Returns } & \multicolumn{4}{|c|}{ Panel B: Stock Returns } \\
\hline$V_{h^{y}}$ & 32.67 & 0 & .54 & 25.60 & 103.07 & 0 & .79 & 69.64 \\
\hline $\operatorname{Corr}_{a, h^{y}}$ & -.477 & 0 & .485 & .423 & -.918 & 0 & .644 & .929 \\
\hline $\operatorname{Corr}_{d^{y}, h^{y}}$ & -.547 & 0 & .023 & .560 & -.871 & 0 & .364 & .823 \\
\hline $\operatorname{Corr}_{h^{a}, h^{y}}$ & 1.000 & 0 & -.306 & -.875 & 1.000 & 0 & -.453 & -.945 \\
\hline$V_{y}$ & 63.99 & 10.79 & 11.22 & 17.77 & 157.77 & 7.21 & 6.27 & 39.95 \\
\hline Corr $_{y, a}$ & .166 & -.426 & -.525 & -.840 & .883 & .661 & .480 & -.945 \\
\hline $\operatorname{Corr}_{y, h^{a}}$ & -.939 & -.547 & -.469 & .624 & -.994 & -.871 & -.773 & .877 \\
\hline$V_{c}$ & 5.02 & 1.51 & 1.33 & 0.33 & 13.61 & 3.19 & 2.79 & .33 \\
\hline $\operatorname{Corr}_{c, a}$ & .467 & .419 & .386 & .168 & .932 & .906 & .901 & .185 \\
\hline$V_{m}$ & 39.58 & 5.55 & 4.72 & 2.72 & 120.17 & 15.20 & 12.81 & 5.30 \\
\hline $\operatorname{Corr}_{m, a}$ & .479 & .469 & .393 & -.238 & .927 & .932 & .903 & -.777 \\
\hline $\operatorname{Corr}_{m, y}$ & .945 & .599 & .576 & .727 & .995 & .888 & .810 & .940 \\
\hline $\operatorname{Corr}_{m, h^{m}}$ & -.994 & -.956 & -.933 & -.937 & -.998 & -.983 & -.973 & -.969 \\
\hline
\end{tabular}

Table 8: Euler Equation Errors

The table shows the coefficient of risk aversion $\gamma$ (first row) that minimizes the root mean squared pricing error on the CRSP value-weighted stock returns and a T-bill return (RMSE in row four). It also shows the average Euler equation errors on the stock return $\left(\right.$ error $\left.^{s t}\right)$ and the T-bill return (error $\left.{ }^{r f}\right)$. For each model, rows five and six report the correlation between model-implied consumption growth and actual consumption growth $\left(\right.$ Corr $_{m, d}=$ $\left.\operatorname{Corr}\left(\Delta c^{m}, \Delta c^{d}\right)\right)$, and the standard deviation of model-implied consumption growth $\left(S t d_{m}=S t d\left(\Delta c^{m}\right)\right)$. The time discount factor is held constant throughout the table at $\beta=.99$. The value for $\gamma$ is held fixed at the value reported in the first row. In panel $\mathrm{A}$, we fix $\sigma=0.28$. In panel $\mathrm{B}$, we set $\sigma=1.12$. The estimation uses the firm value return for $r^{a}$. The Euler equation errors are multiplied by 100; they report a percentage error per quarter.

\begin{tabular}{|c|c|c|c|c|c|c|c|c|c|}
\hline & Model 1 & Model 2 & Model $2_{T V}$ & Model 3 & Model $3_{T V}$ & Model 4 & Model $4_{T V}$ & Reverse & Model 5 \\
\hline \multicolumn{10}{|c|}{ Panel A: EIS.28 } \\
\hline$\gamma$ & 3.71 & 15.93 & 18.44 & 17.02 & 19.90 & 17.49 & 20.74 & 23.09 & 11.37 \\
\hline error $^{\text {st }}$ & 0.34 & -0.07 & -0.09 & -0.17 & -0.23 & -0.20 & -0.29 & -0.28 & 0.66 \\
\hline error $^{r f}$ & -0.24 & 0.05 & 0.07 & 0.12 & 0.17 & 0.14 & 0.21 & 0.21 & -0.60 \\
\hline$R M S E$ & 0.30 & 0.06 & 0.08 & 0.15 & 0.20 & 0.17 & 0.25 & 0.25 & 0.63 \\
\hline $\operatorname{Corr}_{m, d}$ & 0.03 & 0.33 & 0.35 & 0.26 & 0.29 & 0.24 & 0.28 & 1.00 & 0.87 \\
\hline$S t d_{m}$ & 6.17 & 2.48 & 2.40 & 2.09 & 1.99 & 2.01 & 1.89 & 0.65 & 1.84 \\
\hline \multicolumn{10}{|c|}{ Panel B: EIS 1.12 } \\
\hline$\gamma$ & 5.46 & 6.27 & 6.27 & $1 / \sigma$ & $1 / \sigma$ & $1 / \sigma$ & $1 / \sigma$ & $1 / \sigma$ & 3.97 \\
\hline errorst & -0.53 & 0.23 & 0.02 & 0.92 & 0.92 & 0.93 & 0.93 & 0.99 & 0.67 \\
\hline error $^{r f}$ & 0.48 & -0.22 & -0.02 & -0.95 & -0.97 & -0.96 & -0.98 & -1.03 & -0.66 \\
\hline$R M S E$ & 0.50 & 0.23 & 0.02 & 0.94 & 0.95 & 0.94 & 0.95 & 1.01 & 0.66 \\
\hline $\operatorname{Corr}_{m, d}$ & 0.18 & 0.30 & 0.30 & 0.33 & 0.35 & 0.28 & 0.30 & 1.00 & 0.93 \\
\hline$S t d_{m}$ & 7.30 & 6.48 & 6.54 & 2.67 & 2.52 & 2.33 & 2.15 & 0.65 & 1.36 \\
\hline
\end{tabular}


Table 9: Risk Contributions From $c$ and $m-25$ Size and Value Portfolios

The first column gives the average log excess return per quarter, in excess of a 3-month T-bill return $\left(e^{\text {data }}\right)$. The second column adjusts for the Jensen effect by adding $1 / 2$ times the variance of the log excess return $\left(e r_{a d j}^{\text {data }}\right)$. Columns 3-4 give the model's predicted adjusted return $\left(\left(e_{a d j}^{p r e d}\right)\right)$ and the pricing error (error). The last three columns give the risk contribution (price of risk times quantity of risk) to the expected excess return of each asset; the first one of which is the market price of risk on a constant $\left(p_{0}\right)$. The assets are the 25 size and book-to-market decile portfolios from Kenneth French. The return measure $r^{a}$ in the VAR is the firm value return. All numbers are multiplied by 100 . Our model is computed for $\sigma=.28$ and time-varying human wealth share.

\begin{tabular}{l|cc|cc|ccc} 
Portfolio & $e r^{\text {data }}$ & er data & $e r_{a d j}^{\text {pred }}$ & error & $\lambda_{o}$ & $\lambda_{c} \beta_{i c}$ & $\lambda_{m} \beta_{i m}$ \\
\hline S1B1 & 0.073 & 1.296 & 1.547 & -0.251 & 3.775 & 1.138 & -3.366 \\
S1B2 & 1.841 & 2.704 & 1.900 & 0.805 & 3.775 & 1.158 & -3.034 \\
S1B3 & 2.154 & 2.800 & 2.160 & 0.640 & 3.775 & 0.797 & -2.412 \\
S1B4 & 2.792 & 3.381 & 2.661 & 0.720 & 3.775 & 0.810 & -1.924 \\
S1B5 & 3.137 & 3.826 & 2.566 & 1.261 & 3.775 & 0.845 & -2.054 \\
\hline S2B1 & 0.642 & 1.602 & 0.651 & 0.951 & 3.775 & 1.123 & -4.247 \\
S2B2 & 1.813 & 2.470 & 1.315 & 1.156 & 3.775 & 0.894 & -3.355 \\
S2B3 & 2.432 & 2.947 & 1.854 & 1.093 & 3.775 & 0.773 & -2.694 \\
S2B4 & 2.605 & 3.103 & 2.272 & 0.832 & 3.775 & 0.747 & -2.250 \\
S2B5 & 2.975 & 3.572 & 2.316 & 1.256 & 3.775 & 0.826 & -2.285 \\
\hline S3B1 & 1.123 & 1.903 & 0.995 & 0.908 & 3.775 & 0.947 & -3.727 \\
S3B2 & 1.998 & 2.505 & 1.774 & 0.731 & 3.775 & 0.720 & -2.721 \\
S3B3 & 2.105 & 2.545 & 2.127 & 0.418 & 3.775 & 0.686 & -2.334 \\
S3B4 & 2.519 & 2.953 & 2.465 & 0.488 & 3.775 & 0.638 & -1.948 \\
S3B5 & 2.724 & 3.261 & 2.031 & 1.230 & 3.775 & 0.824 & -2.568 \\
\hline S4B1 & 1.425 & 2.049 & 1.243 & 0.806 & 3.775 & 0.843 & -3.375 \\
S4B2 & 1.580 & 2.035 & 1.581 & 0.453 & 3.775 & 0.662 & -2.856 \\
S4B3 & 2.366 & 2.758 & 2.262 & 0.496 & 3.775 & 0.565 & -2.078 \\
S4B4 & 2.331 & 2.721 & 2.251 & 0.470 & 3.775 & 0.621 & -2.144 \\
S4B5 & 2.524 & 3.062 & 2.178 & 0.884 & 3.775 & 0.808 & -2.405 \\
\hline S5B1 & 1.415 & 1.824 & 2.105 & -0.280 & 3.775 & 0.665 & -2.335 \\
S5B2 & 1.538 & 1.861 & 2.088 & -0.227 & 3.775 & 0.560 & -2.246 \\
S5B3 & 1.925 & 2.195 & 2.326 & -0.131 & 3.775 & 0.556 & -2.005 \\
S5B4 & 1.854 & 2.149 & 2.429 & -0.280 & 3.775 & 0.546 & -1.892 \\
S5B5 & 1.911 & 2.323 & 2.490 & -0.167 & 3.775 & 0.797 & -2.082 \\
\hline & & & & & & &
\end{tabular}


Table 10: Model Comparison

The table shows the market prices of risk obtained from the cross-sectional regression $\overline{e r}^{i}=\lambda_{0}+\lambda_{c} \beta_{i c}+\lambda_{m} \beta_{i m}+\epsilon^{i}$. The risk exposures $\left(\beta_{i c}, \beta_{i m}\right)$ are obtained from a first step time series regression. Standard errors are Shankencorrected. The last two lines report the root mean squared pricing error across all portfolios, and the adjusted $R^{2}$ from the second step regression. The test asset returns are the log real excess returns on the 25 Fama-French size and value portfolios. The estimation uses the firm value return for $r^{a}$ and $\sigma=.28$ in the upper panel, $\sigma=1.12$ in the lower panel. All numbers are multiplied by 100 .

\begin{tabular}{|c|c|c|c|c|c|c|c|c|c|}
\hline MPR & Model 1 & Model 2 & Model $2_{T V}$ & Model 3 & Model $3_{T V}$ & Model 4 & Model $4_{T V}$ & Reverse & Model 5 \\
\hline \multicolumn{10}{|c|}{ Panel A: EIS.28 } \\
\hline$\lambda_{0}$ & 4.73 & 3.73 & 3.36 & 3.39 & 3.22 & 3.21 & 3.20 & 4.26 & 3.78 \\
\hline$\sigma_{\lambda_{0}}$ & 0.83 & 0.68 & 0.75 & 0.82 & 0.90 & 1.03 & 1.10 & 1.17 & 0.92 \\
\hline$\lambda_{c}$ & -3.24 & -0.60 & -0.51 & 0.09 & 0.32 & 0.47 & 0.58 & 0.58 & 0.53 \\
\hline$\sigma_{\lambda_{c}}$ & 1.51 & 0.37 & 0.40 & 0.55 & 0.68 & 0.67 & 0.78 & 0.31 & 0.88 \\
\hline$\lambda_{m}$ & -2.25 & -2.11 & -3.11 & -0.70 & -0.66 & -0.74 & -0.73 & 6.37 & 11.99 \\
\hline$\sigma_{\lambda_{m}}$ & 1.03 & 1.47 & 1.73 & 0.38 & 0.42 & 0.39 & 0.43 & 2.41 & 4.75 \\
\hline RMSE & 0.82 & 0.84 & 0.84 & 0.83 & 0.83 & 0.81 & 0.80 & 0.72 & 0.76 \\
\hline$R^{2}$ & 36.91 & 30.44 & 31.13 & 32.87 & 35.06 & 42.67 & 45.87 & 63.77 & 47.33 \\
\hline \multicolumn{10}{|c|}{ Panel B: EIS 1.12 } \\
\hline$\lambda_{0}$ & 4.29 & 3.83 & 3.96 & 4.25 & 4.46 & 4.08 & 4.69 & 3.55 & 2.47 \\
\hline$\sigma_{\lambda_{0}}$ & 0.84 & 0.73 & 0.81 & 1.00 & 1.09 & 0.82 & 0.99 & 0.92 & 0.65 \\
\hline$\lambda_{c}$ & -1.33 & -1.44 & -0.72 & -0.18 & -0.00 & -0.69 & -0.59 & 0.55 & 0.22 \\
\hline$\sigma_{\lambda_{c}}$ & 1.25 & 1.27 & 1.54 & 0.59 & 0.65 & 0.34 & 0.34 & 0.30 & 0.56 \\
\hline$\lambda_{m}$ & -2.05 & -2.00 & -1.71 & -0.72 & -0.65 & -0.60 & -0.71 & 0.89 & -0.92 \\
\hline$\sigma_{\lambda_{m}}$ & 1.03 & 1.06 & 1.13 & 0.43 & 0.47 & 0.30 & 0.31 & 0.32 & 0.96 \\
\hline RMSE & 0.83 & 0.84 & 0.83 & 0.81 & 0.78 & 0.83 & 0.83 & 0.72 & 0.85 \\
\hline$R^{2}$ & 35.96 & 30.94 & 32.02 & 37.42 & 45.54 & 34.70 & 36.93 & 64.44 & -4.24 \\
\hline
\end{tabular}

